Florida International University

FIU Digital Commons

FIU Electronic Theses and Dissertations

University Graduate School

$7-28-2000$

\title{
Relationship between personality hardiness and critical care nurses' perception of stress and coping in the critical care environment
}

Catherina Ivette Chang

Florida International University

DOI: $10.25148 /$ etd.FI14060139

Follow this and additional works at: https://digitalcommons.fiu.edu/etd

Part of the Nursing Commons

\section{Recommended Citation}

Chang, Catherina Ivette, "Relationship between personality hardiness and critical care nurses' perception of stress and coping in the critical care environment" (2000). FIU Electronic Theses and Dissertations. 2107.

https://digitalcommons.fiu.edu/etd/2107

This work is brought to you for free and open access by the University Graduate School at FIU Digital Commons. It has been accepted for inclusion in FIU Electronic Theses and Dissertations by an authorized administrator of FIU Digital Commons. For more information, please contact dcc@fiu.edu. 
FLORIDA INTERNATIONAL UNIVERSITY

Miami, Florida

RELATIONSHIP BETWEEN PERSONALITY HARDINESS AND CRITICAL

CARE NURSES' PERCEPTION OF STRESS AND COPING IN THE CRITICAL

CARE ENVIRONMENT

A thesis submitted in partial fulfillment of the

requirements for the degree of

MASTER OF SCIENCE

in

NURSING

by

Catherina Ivette Chang 
To: Dean Ronald Berkman

College of Health Sciences

This thesis, written by Catherina Ivette Chang, and entitled Relationship Between Personality Hardiness and Critical Care Nurses' Perception of Stress and Coping in the Critical Care Environment, having been approved in respect to style and intellectual content, is referred to you for judgment.

We have read this thesis and recommend that it be approved.

Tomas Madayag

Patricia Messmer

John Lowe, Major Professor

Date of Defense: July 28,2000

The thesis of Catherina Ivette Chang is approved.

Dean Ronald Berkman
College of Health Sciences

Dean Richard L. Campbell Division of Graduate Studies

Florida International University, 2000 
(C) Copyright 2000 by Catherina Ivette Chang

All rights reserved. 


\section{DEDICATION}

I dedicate this thesis to my parents, for their invaluable support, guidance, and love. They have always encouraged me to pursue higher dreams. I would also like to dedicate this thesis to my two wonderful sisters, Nancy and Claudia, who have always been there to inspire me and provide me with words of faith and strength. I wish to dedicate this research project to my family, especially aunt Rithy for her words of inspiration, and her willingness to assist me at all times throughout the completion of this project. I also wish to dedicate this thesis to the two new additions to our family, Rick and Hannah, two wonderful blessings to our family.

Most of all, I would like to dedicate this piece of work to God for giving me His guidance to make the right decisions and the courage to carry them through. 


\section{ACKNOWLEDGMENTS}

I wish to thank my Major Professor, Dr. John Lowe for his guidance, knowledge, and assistance in following every step of the research process of this thesis. I would like to extend my thanks to him for his time and patience during the correction of the proposal and the chapters of this thesis. I would also like to thank Dr. Tomas Madayag for his support of this project since its origins. Without his support and the assistance from the members of my thesis committee, the completion of this project would not have been made possible. Many thanks should also be extended to Dr. Patricia Messmer for her invaluable guidance in the development of this research project from start to end. Her knowledge of the research process at the facility where this study took place and her assistance with the submission and approval of the initial proposal and corrections of the thesis draft were instrumental to the finalization of this project. I would also like to acknowledge Dr. Douglas Coffin who encouraged me to pursue this research project when it was in its initial steps. He will always be remembered.

I would like to thank Ms. Catherine Johnson, Ms. Gilda Saul, and Ms. Rachel Banks for their kind assistance in the data collection of this project. I wish to thank three special friends: Modesta, Manuela, and Alvaro for their words of encouragement and friendships.

I would also like to extend many thanks to all the nurses who participated in this study. Without their participation, this study would not have been made possible. 


\title{
ABSTRACT OF THE THESIS
}

\section{RELATIONSHIP BETWEEN PERSONALITY HARDINESS AND CRITICAL CARE NURSES' PERCEPTION OF STRESS AND COPING IN THE}

\author{
CRITICAL CARE ENVIRONMENT \\ by \\ Catherina Ivette Chang \\ Florida International University, 2000 \\ Miami, Florida \\ Professor John Lowe, Major Professor
}

The purpose of this study was to determine the relationship between critical care nurses' perception of stress, their ability to cope with stress, and the hardiness personality they possess while working in the critical care environment. A non-experimental, descriptive, correlational survey design was applied to a convenience sample of 50 registered nurses employed in the critical care units of a South Florida health care facility. The data collection methods included a demographic survey, the Perceived Stress Scale, the Health-Related Hardiness Scale, and the COPE inventory. The results of this study demonstrated that critical care nurses are able to cope effectively despite their perception of high levels of stress. This study also determined that critical care nurses uphold high personality hardiness characteristics. The demographic variables of gender, age, years of nursing experience, years at present job, and level of education also revealed statistical significance. Further research is recommended to identify the 
influence of other variables such as culture, work hours, and level of job satisfaction in the critical care nurses' coping with stress and hardiness personality. The identification of instruments that may be capable of measuring any relationships between those possible variables and the constructs of hardiness and coping in the domain of nursing are also advocated, particularly in the critical care nursing population. 


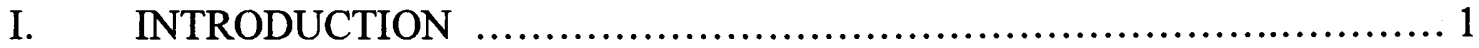

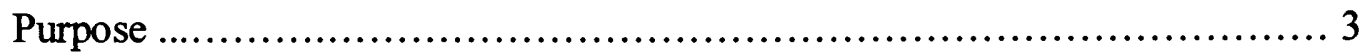

Problem Statement ......................................................... 4

Significance of the Study ...................................................... 4

Definition of Terms .......................................................... 5

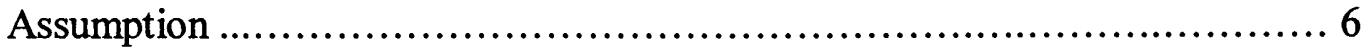

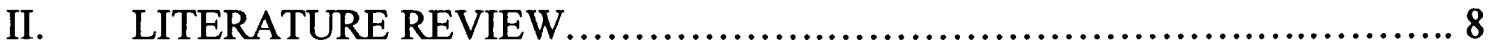

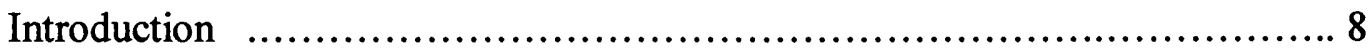

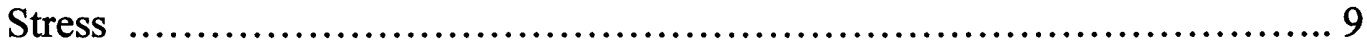

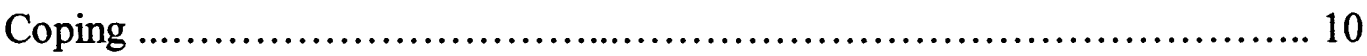

General Adaptation Syndrome

Personality and hardiness characteristic .....................................12

Stress in the critical care setting ............................................. 13

Conceptual Framework .................................................. 14

Hypotheses ............................................................... 17

Research Variables ..................................................... 18

Research Questions.................................................. 18

Operational Definitions............................................... 18

III. METHODOLOGY ..................................................... 20

Design and Setting....................................................... 20

Sample and Sampling Method ....................................... 20

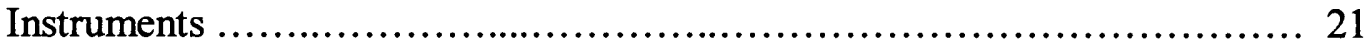

Demographic Information Questionnaire ................................ 21

Perceived Stress Scale (PSS) .............................................. 21

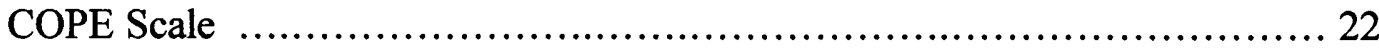

Health-Related Hardiness Scale (HRHS) .................................. 24

Protection of Human Rights ................................................ 25

Data Collection Procedures ............................................... 26

Data Analysis ............................................................. 27

IV. PRESENTATION OF FINDINGS ........................................ 28

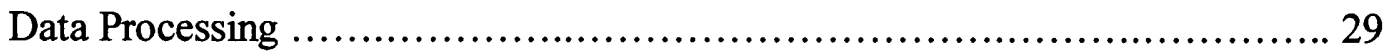

Perceived Stress Scale (PSS) Data Processing ................................ 30

COPE Scale Data Processing ................................................. 30

Health - Related Hardiness Scale (HRHS) Data Processing .................... 30

Statistical Modeling ......................................................... 31

Demographic Results ................................................... 32

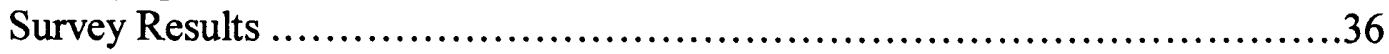

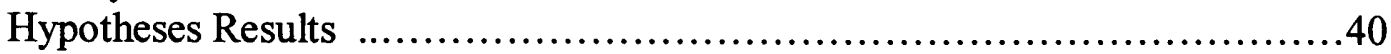


V. DISCUSSION, CONCLUSION, IMPLICATIONS,

LIMITATIONS, AND RECOMMENDATIONS.

Discussion ................................................................ 44

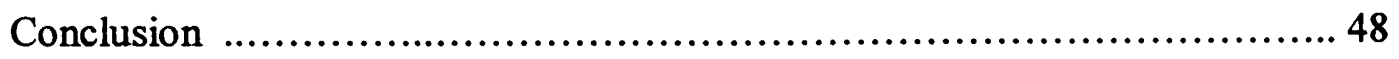

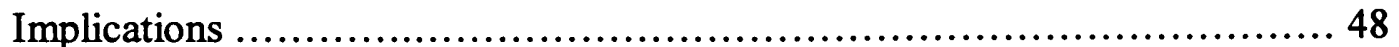

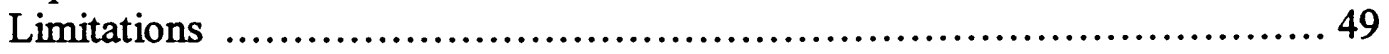

Recommendations .................................................... 51

LIST OF REFERENCES...............................................53

APPENDICES.............................................................. 56 


\section{LIST OF TABLES}

TABLE

PAGE

I. Frequency Distribution of Respondents' Age .......................... 33

II. Frequency Distribution of Respondents' Gender ........................... 33

III. Frequency Distribution of Respondents' Highest level of Education ...................................................... 34

IV. Frequency Distribution of Respondents' Number of Years in Present Job ................................................... 34

VI. Frequency Distribution of Respondents' Number of Years in Nursing Experience ..................................... 35

VII. Frequency Distribution of Respondents' Work Schedule ................... 35

VIII. Frequency Distribution of Respondents' Job Classification .................. 36

IX. Survey Statistical Summary of Results f............................... 37

X. Bivariate Pearson Correlation Study for Hypothesis I ....................... 41

XI. Bivariate Pearson Correlation Study for Hypothesis II ....................... 42

XII. Bivariate Pearson Correlation Study for Hypothesis III ....................... 43 
FIGURES

PAGE

1. Sample Excel Spreadsheet Data Processing Entry for the COPE survey 29

2. Statistical Modeling Using SPSS 32

3. PSS Score Histogram 38

4. COPE Inventory Score Histogram 39

5. HRHS Score Histogram 40 


\section{CHAPTER I}

\section{INTRODUCTION}

Working in the critical care environment is an interesting and challenging experience for the nurse who engages to become a part of such a highly technological environment. The critical care nurse takes on diverse roles: (a) teacher; (b) comforter for the confused, anxious, or in pain; (c) friend and counselor for the family of the dying; and (d) decision-maker in critical situations (Houston, 1993). These type of roles can become quite stressful at times, especially when nurses have to face ethical dilemmas concerning the management of patients' complex health problems as a result of advances in health care technology and changes in health care delivery (Erlen \& Sereika, 1997).

Jackson (1997) cites that health care professionals, in general, face occupational stressors to which they seem to be able to cope constructively at times. For those health care professionals who are unable to cope, stress may show in different ways, such as high staff turnover, low morale, and burnout. Burnout occurs when the individuals' personal resources are depleted faster than they can be replenished by the increasing work demands, leading to a sense of depersonalization and emotional exhaustion (Jackson, 1997). As a result of this burnout, work-related problems may arise such as:

(a) staff conflicts, (b) absenteeism, (c) lowered morale, and (d) markedly decreased productivity, and thus compromising patient care (Sawatzky, 1996). The financial health and profitability of health organizations are also affected (Jackson, 1997).

Previous studies on stress in nurses have identified its adverse effects on the nurses' physical health, manifested by symptoms such as headaches, skin rashes, 
gastrointestinal disorders, and weight fluctuations (Sawatzky, 1996). Critical care nurses are trained, educated, and expected to save lives, sometimes at the expense of personal values and beliefs. As a result, critical care nurses may face: (a) personal role conflicts, (b) loss of sense of self, and (c) chronic cumulative stress that may impact on patient care and the integrity of the critical care nurses' mental and physical well-being (Houston, 1993).

Selye (1956) defines stress as a state that is real and concrete, "manifested by a specific syndrome which consists of all the non-specifically induced changes within a biologic system" (p.54). Life is described as a process of adaptation to the circumstances in which individuals exist, leading to a state of health and happiness if the individuals were to adjust successfully; and illness and unhappiness, if they were to fail to cope (Selye, 1956). Thus, stress is unavoidable, but individuals "can learn a great deal about how to keep its damaging effects to a minimum" (Selye, 1956, p.viii). Lazarus (1994) describes the process of adaptation or coping as a problem-solving approach, important in shaping the person's emotions (Lazarus, 1994). Coping is defined as the "cognitive and behavioral efforts to manage specific external and/or internal demands that are appraised as taxing or exceeding the resources of the person" (Monat \& Lazarus, 1991, p.210). Coping shapes the person-environment relationship, creating an emotional response. For that reason, coping is noted to be the mediator of the emotional response (Monat \& Lazarus, 1991).

Individuals, in general, have been noted to cope with stress in different ways, influenced by personal factors such as: constitutional strengths, social support, health practices, and personality dispositions, which lead some individuals to not become ill 
despite their stressful lives (Kobasa, Maddi, and Kahn, 1982). Kobasa et al. (1982) identified the presence of a certain personality disposition, hardiness, composed of characteristics that would function as resistance resources when encountering stressful life events. Kobasa et al. (1982) described hardiness as composed of three dimensions: (a) commitment, (b) control, and (c) challenge. Hence, hardy persons are more likely to appraise a situation as challenging rather than threatening. Hardy individuals have a higher sense of commitment to work and to themselves; and they feel a greater sense of control over their lives, viewing stressors as potential opportunities for change (Kobasa et al., 1982).

The personality construct of hardiness is of great interest within the research arena because of its reported role as a buffer between stressors and nursing burnout as noted from various previous studies (Simoni \& Paterson, 1997). A study conducted by Simoni and Paterson (1997) identified hardiness, rather than particular workplace stressors, to be the variable with significant relationship to burnout among both Intensive Care Unit and non-Intensive Care Unit nurses. Nurses in both settings who scored higher levels of hardiness had less burnout. Therefore, this study will investigate the relationship between the critical care nurses' perception and coping with stress, and the personality hardiness that they possess in their working environment

\section{PURPOSE}

The purpose of this study is to determine the relationship between critical care nurses' perception of stress, their ability to cope with stress, and the hardiness personality they possess while working in the critical care environment. 


\section{PROBLEM STATEMENT}

What is the relationship between critical care nurses' perception and coping with stress and the level of personality hardiness they possess? There are three facets to the research problem:

a) Critical care nurses have an increased exposure to stress in the critical care environment.

b) Critical care nurses face an increased risk for burnout.

c) Those critical care nurses who have higher personality hardiness face less incidence of burnout.

\section{SIGNIFICANCE OF THE STUDY}

Stress has been acknowledged to be a significant problem in the critical care area since the inception of critical care units almost four decades ago. The objective of most intensive care nursing stress studies has been to describe the stressors experienced in this environment (Sawatzky, 1996). Although nursing literature is filled with the description of work stressors in the critical care environment, the perception of these stressors is seldom acknowledged (Sawatzky, 1996). Understanding how staff nurses cope with stress will enhance the use of interventions to reduce stress and will improve retention and recruitment of professional nurses. The above will, therefore, influence positively on the quality of patient care (Moore \& Peterson, 1992).

This study may contribute to the body knowledge of nursing by providing a better understanding of critical care nurses' perception and coping with stress. All organizations and individuals should take a proactive approach to reducing stress at 
work by way of (a) social support, (b) stress management training, (c) counseling, (d) critical incident debriefing, and (e) managerial support (Jackson, 1997). Stress in the workplace is also an issue that should be addressed by (a) administration, (b) teachers, and (c) nurses. The reduction of stress potentially affects (a) patient care delivery, (b) nurses retention, and (c) the mental health of care providers (Houston, 1993). Boyle, Grap, Younger, and Thornby (1991) noted the importance of remembering the character of nursing as a profession that is stressful, especially when the health care system is facing a critical nursing shortage. Boyle et al. (1991) supported the importance of preventing "those who are brightly burning from becoming burned out" (p.857).

The results of this study have implications for critical care nursing practice and administration as they will furnish updated information on the identification of the presence of stress and its impact on the nurses' work. The development of programs can be implemented to improve the coping skills of nurses (Sawatzky, 1996).

\section{DEFINITION OF TERMS}

Stress: disruption caused by a noxious stimulus (Benoliel, McCorkle, Georgiadou, Denton, and Spitzer, 1990). The element(s) causing stress may place demands on the individuals which tax or exceed their adjustive resources (Lazarus, 1976).

Stressors: agents or factors that possess the ability to produce stress (Selye, 1956). Job-related stress: an event in the workplace that produces a variety of psychological symptoms such as diminished work performance, low morale, and personal dysfunction (Lobb \& Reid, 1987). 
Coping: form of problem solving in which the stakes are the person's well being and the person is not entirely clear about what to do; what the person does to handle stressful emotionally-charged demands (Lazarus, 1976).

Hardiness: a personality disposition composed of commitment, control, and challenge. Hardiness may facilitate the kind of coping that leads to successful resolution of a stressful situation (Kobasa et al., 1982).

Burnout: syndrome of physical, emotional, and mental exhaustion, involving the development of a negative self-concept, negative job attitude, and lack of concern for clients. Burnout has been characterized as a maladaptive psycho-physiological and behavioral response to occupational stressors (Boyle et al., 1991).

Critical care unit: a designed hospital unit that treats patients with life threatening illnesses using sophisticated equipments, monitoring techniques, and invasive procedures (Furukawa, 1996).

Critical care nurse: a registered nurse working in a critical care unit. Adaptation: adjustment of the individual's struggle to get along or survive in his or her social and physical environments (Lazarus, 1976).

Personality: stable psychological characteristics of the individual that dispose him or her with situations in certain distinctive ways. Personality also refers to stable variations in the techniques or processes of adjustment (Lazarus, 1976).

\section{ASSUMPTIONS}

Each individual has the ability to adapt to stress based on the unique characteristics that make up his or her personality. 
Each individual has a different level of threshold to stress.

Inability to cope with stress results in negative consequences: physically, mentally, and emotionally.

A hardy individual has a higher perception of coping with stress.

In summary, chapter I describes the purpose of this study, its significance, definition of central concepts, and assumptions under investigation. 


\section{CHAPTER II}

\section{LITERATURE REVIEW}

\section{INTRODUCTION}

Over the years there has been an increased focus of attention towards the study of stress and burnout experienced by nurses, as well as the role of hardiness in the nurses' coping with stress. Especially in the area of critical care nursing, nurses must use coping mechanisms not normally needed in order to cope with stress (Houston, 1993). Studies focusing on the aspect of stress and nursing strive to provide a better understanding of the subject, while encouraging nursing leaders and health care organizations to look into the creation of better conditions in an environment that allows for health practitioners to fulfill their role as caregivers (Holcombe, 1995). The environment, in which we live and work, has a profound influence on our professional and interpersonal behavior. The development of an environment where others are inspired to generate ideas, implement new practices, and promote critical thinking are all the responsibilities of leaders in health care (Holcombe, 1995). One answer to such issue lies in the theory of hardiness, first identified by Kobasa (1979) as a stress buffer on stress-illness relationships. Holcombe (1995) cited that a better understanding of the concepts of hardiness and stress could influence how nursing leaders create environments supportive to individuals who possess hardiness personality characteristics. These environments may also be successful in preventing burnout and stress-related illness in caregivers and recipients of that care. Moreover, there are evolving studies that show that specific interventions can increase the individuals' 
hardiness, improving their ability to cope with stress and illness. The provision of such interventions could also lead to improved patient outcomes (Holcombe, 1995).

\section{STRESS}

Lazarus (1976) states that "in order to survive and flourish, humans and animals must deal effectively with a variety of physical and social demands" (p. 43), or pressures that cannot be ignored lest there be damaging consequences (Lazarus, 1976). Stress can be defined as the disruption caused by a noxious stimulus, or a transaction that arises out of interchanges between the person and the environment (Benoliel, McCorkle, Georgiadou, Denton, \& Spitzer, 1990). As described by Lazarus (1976), stress may take the form of environmental conditions or physical stressors, such as: (a) extreme cold, (b) heat, (c) microorganisms, or (d) physical injuries among others. Stress may also take the form of psychosocial stressors, where individuals sense danger or recognize damage and must act to protect themselves against this or try to overcome the damage. However, stress depends not only on the external condition, but also on the vulnerability of the individual and the adequacy of his or her system of defenses based on his or her psychological or physiologic construction. For that reason, people may react to the same stressor in diverse ways, some undisturbed and others disorganized, dazed, and panicky (Lazarus, 1976). Numerous research studies have shown that there are individual differences in the perception of stressors and on the concept of coping (Lazarus, 1966). Thus, individual perceptions and coping mechanisms will be reflected in the stress response and the subsequent level of adaptation established (Pollock, 1984). The way an individual copes appears to be a learning experience that begins at 
the moment of birth and continues throughout life, wherein the person adjusts to environmental demands by problem solving. During this process, the individual generates strong emotions such as anger, fear, anxiety, guilt, and shame, especially when the environmental demands and opportunities involve high stakes and entail frustration, threat, and conflict (Lazarus, 1976). Selye (1956) further commented on stress as "the spice of life", meaning that stress can be desirable as well as devastating. Stress is further considered to be a perfectly normal human state and that the organism is under various degrees of stress in those conditions which are related to happiness as well as those concerned with sadness (Humphrey, 1988).

\section{COPING}

Lazarus (1976) describes coping as the individual's ability to handle those stressful or emotionally charged demands through the use of direct actions. The individual's coping is accomplished through the use of different methods of selfprotection: aggression, avoidance, inaction, or apathy. The person may also utilize palliative measures directed at reducing or eliminating the distressing features of a stress emotion once it has been brought about by the individual's encounter with the environment (Lazarus, 1976). Palliative action is accomplished through the use of defense mechanisms such as: identification, displacement, repression, suppression, denial, reaction formation, or projection (Lazarus, 1976).

Moreover, Carver, Scheier, and Weintraub (1989) reported the existence of tendencies or strategies that either assist or impede the individual's adaptive coping. Such tendencies were measured by different scales, which they incorporated into the 
COPE inventory. Such dimensions consist of: (a) active coping, (b) planning or thinking about how to cope with a stressor, (c) suppression of competing activities, (d) restraint coping or waiting until an appropriate opportunity to act presents, and (e) seeking social support for informative or emotional reasons (Carver et al., 1989). Other strategies noted by Carver et al. (1989) involve focusing on and venting of emotions; positive reinterpretation and growth by construing a stressful transaction in positive terms and leading the person to continue active, problem-focused coping actions; denial or acceptance of the stressful situation. There is also the tendency to turn to religion as: (a) a source of emotional support, (b) vehicle for positive reinterpretation and growth, or (c) an active form of coping response (Carver et al., 1989). In contrast, two dysfunctional coping tendencies have been noted: (a) behavioral disengagement or reducing the individual's efforts to deal with the stressor, and (b) mental disengagement by way of activities aimed at distracting the person from thinking about the goal with which the stressor was interfering (Carver et al., 1989).

\section{GENERAL ADAPTATION SYNDROME}

Selye (1956) described the general adaptation syndrome as a physiological response of the body in an effort to deal with stress. The physiological response consists of three stages:

(a) the alarm stage where the body shows the changes characteristic of the first exposure to a stressor;

(b) the resistance stage, which ensues if continued exposure to the stressor is compatible with adaptation, and 
(c) the exhaustion stage, in which the mobilizing organ systems break down and lead to breakdown of the defenses in response to long, continued exposure to the same stressor. The signs of the alarm reaction reappear, but now they are irreversible, and the individual dies (Humphrey, 1988).

\section{PERSONALITY AND HARDINESS CHARACTERISTIC}

The way a person copes with a stressor varies, supporting the notion that personality factors are linked closely with coping processes (Zeidner \& Endler, 1996). Kobasa et al. (1982) noted the emphasis in stress and illness research has shifted towards the study of resistance resources that could neutralize the debilitating effects of stressful life events. Such resources could include (a) constitutional strengths, (b) social supports, (c) health practices, and (d) personality dispositions (Kobasa et al, 1982). Kobasa (1979) further proposed hardiness as a constellation of personality characteristics that would function as a resistance resource in the encounter with stressful life events. The personality dispositions of hardiness cited by Kobasa et al. (1982) are composed of (a) commitment, (b) control, and (c) challenge. The commitment disposition is expressed as a tendency to involve rather than alienate oneself from an event; thus, identifying with and finding meaningful the events, things, and persons of the environment (Kobasa, 1982). The control disposition is expressed as a tendency to feel and act as if one is influential rather than helpless in the face of the varied contingencies of life. Therefore, stress resistance is enhanced by increasing the perception of events as a natural outgrowth of one's actions, and not as foreign, unexpected, and overwhelming experiences (Kobasa, 1982). Last, the challenge 
disposition is expressed as the belief that change is normal in life. The stressful event is viewed as an incentive for growth; events are therefore colored as stimulating rather than threatening (Kobasa, 1982). By fostering openness and flexibility, challenge allows the integration and effective appraisal of exceedingly incongruent events (Kobasa, Maddi, \& Kahn, 1982).

\section{STRESS IN THE CRITICAL CARE SETTING}

Previous studies involving the critical care setting have noted stress factors to include: (a) the presence of interpersonal communication problems, (b) the nurses' need for and lack of an extensive knowledge base, (c) the critical care environment itself, and (d) the requirements of patient care (Jacobson \& Mc Grath, 1983).

Often nurses are expected or they expect themselves to do near the impossible in providing highly skilled care and comfort. Nurses can be confronted with unpleasant, distasteful, and frightening experiences daily, including unexpected sudden death and prolonged dying (Benoliel et al., 1990). Other stressors identified in the area of nursing include: (a) the exposure to sick and injured patients, (b) responsibilities for proper use of complex technical equipment, (c) heavy workload, (d) vigilance for signs of patients going bad, and (d) appropriate actions in response to emergency situations (Benoliel et al., 1990). There is also an increased awareness of the nurses' mortality and the mortality of their patients (Erlen \& Sereika, 1997). Nurses have also found that there is more stress in (a) keeping informed with new developments, (b) having too much to do, (c) too many interruptions, (d) not enough staff to do the work, and (e) the ever increasing acuity of a patient's condition, among others (Erlen \& Sereika, 1997). Other 
studies have identified signs that reveal nurses to be emotionally distressed in their work, such as depression characterized by: (a) sleep disorders, (b) dreams laden with conflict, (c) inability to detach emotionally from the job, (d) repetitive accidents, and (e) guilt over taking time off (Benoliel et al., 1990).

\section{CONCEPTUAL FRAMEWORK}

The conceptual framework for this study was chosen from Pollock's adaptation nursing model (1984), revised by Sawatzky (1996). On the bases of Lazarus (1994), Selye (1956), and Roy's works (1971), Pollock (1984) views the concept of stress as a combination of physiological and psychological phenomena. The phenomena that results in stress includes (a) the actual stressful event or stressor, (b) the individual's perception of the stressor, (c) the external and internal mediating factors, and (d) the manifestations of the response. Pollock (1984) operationally defines the contextual or external mediating factors of stress as selected demographic variables, which in this study would include (a) age, (b) employment status, (c) education, (d) nursing experience, and (e) years of work at present job setting. Pollock (1984) further classifies Kobasa's (1984) personality characteristic of hardiness as the internal mediating factor in determining the individual's level of physiologic and psychological adaptation through its mediating effect on stress perception and successful coping (Sawatzky, 1996).

Kobasa (1979) first introduced the personality construct of hardiness as an attribute that moderates stress-illness relationships. This construct was taken from an existential perspective, as a characteristic that enables individuals to remain healthy 
despite high levels of stress, while perceiving each stressful event as an opportunity for mastery and personal growth (Pollock \& Duffy, 1990). In addition, development of the health-related hardiness construct included integration of concepts from (a) coping, (b) adaptation, and (c) developmental tasks of adulthood. In 1986, Pollock developed the Health-Related Hardiness Scale (HHRS) using the theoretical definitions of healthrelated control, commitment, and change. Control was defined as the sense of mastery of self-confidence needed to appraise and interpret health stressors appropriately. Commitment was defined as the motivation and competence to effectively cope with the threat of a health stressor. And challenge was defined as the reappraisal of health stressors as stimulating and potentially beneficial (Pollock, 1984).

The General Adaptation Syndrome (GAS) was developed by Selye (1956) as a result of extensive research on the area of physiological stress, where he noticed the physiological reactions of the stressed organisms to be universal and consisting of a pattern of defense against the assault. Selye (1979) described stress to be present during the entire course of exposure to a nonspecific demand, whether it was of short duration or prolonged over many years. Stress was further defined to occur as a result of tensions: (a) within a setting, (b) from the restraining influence of social taboos or traditions, or (c) any situation in life that made demands upon the individual's adaptive mechanisms (Selye, 1979). Selye (1979) identified physiological changes in response to stress, such as the release of adrenocorticotrophic hormone by the pituitary gland, enlargement of the adrenal cortex, shrinkage of the thymus gland, spleen, and lymph nodes; and the disappearance of eosinophils. Stress was also likely to produce ulcers in the stomach, duodenum, and intestines; of which if defenses were severe and prolonged, 
illness would occur. Selye (1979) further postulated the stages of alarm, resistance, and exhaustion; where defenses played a double role as they aided in the defense of the physiological integrity of the person and contributed to the development of ailments (Lazarus, 1976).

Another theorist, Lazarus (1976) viewed stress as consisting of three processes:

(a) Primary appraisal or the process of perceiving a threat to oneself,

(b) Secondary appraisal or the process of bringing to mind a potential response to the threat (Carver, Scheier, and Weintraub, 1989), and

(c) Coping or the process of executing that response (Carver et al., 1989).

Lazarus (1976) described coping as a form of problem solving in which the stakes were the person's well being and the person was not entirely clear about what to do. According to Lazarus (1976), coping refers to what the person does to handle stressful or emotionally charged demands by way of direct actions or in a palliative form. By direct actions, the individual takes active steps to eliminate or reduce the stressor. If the action succeeds, the signs of danger recede and positive emotional reactions take place; otherwise, stress emotions are likely to occur in the form of depression, shame, guilt, anxiety, anger, or fear (Lazarus, 1976). Other forms of direct action include aggression or attack on the agent that is judged to be harmful; avoidance and escape; or apathy, meaning the complete absence of any impulse to cope with the threat because of the absence of alternatives. In contrast, coping in a palliative form includes the use of defense mechanisms such as identification, displacement, repression, denial, reaction formation, projection, and intellectualization (Lazarus, 1976). 
Sister Callista Roy developed the Roy Adaptation Model in 1964, which

consists of the four elements of person, environment, health, and nursing. According to this theorist, individuals are viewed as living systems in constant interaction with their environment. The individual possesses an adaptive system that has inputs of stimuli and adaptation level, outputs as behavioral responses that serve as feedback, and control processes known as coping mechanisms. The adaptive system has input coming from the external environment as well as from the person (George, 1995). Roy identified inputs as focal, contextual, and residual stimulus. Focal stimuli consisted of the input confronting the person most immediately. Contextual stimuli consisted of those of the person's internal and external world that could have a positive or negative influence on the situation. Residual stimuli consisted of those internal or external factors whose current effects were unclear (Roy \& Andrews, 1991). Outputs of the individual consisted of those responses that could be adaptive, promoting the integrity of the person; or ineffective, if they did not support the goals of survival, growth, reproduction, and mastery (George, 1995). Roy also identified the use of coping mechanisms called regulator subsystems, which had chemical, neural, or endocrine transmitters in nature; and the cognator subsystem which had output responses related to the higher brain functions of perception, judgment, and emotion (George, 1995).

\section{HYPOTHESES:}

1. Critical care nurses with higher hardy personality characteristics will report a higher degree of coping with stress than those with less hardy personality characteristics. 
2. Critical care nurses with higher degree of coping will report less perception of stress from those with lesser degree of coping.

3. Critical care nurses with higher hardy personality traits will report a lesser perception of stress from those with lesser hardy personality traits.

\section{RESEARCH VARIABLES:}

For the purpose of this study:

The independent variables will be the work environment and the hardy personality trait.

The dependent variables will be the job-related stress and the nurses' perception of such stress.

\section{RESEARCH QUESTIONS:}

What is the relationship between the hardy personality characteristic in the critical care nurses and their perception of stress?

What is the relationship between the critical care nurses' perception of stress and actual coping with it?

\section{OPERATIONAL DEFINITIONS:}

Stress: The respondents' perception of their feelings and thoughts as measured by the Perceived Stress Scale (PSS) developed by Cohen, Kanauk, and Mermelstein (1983). Coping: The respondents' appraisal of their coping in a stressful situation measured by the COPE scale developed by Carver, Scheier, and Weintraub, 1989). 
Personality hardiness: The respondents' personality characteristic traits of healthrelated control, commitment, and challenge as measured by the Health-Related Hardiness Scale (HHRS) developed by Pollock (Pollock \& Duffy, 1990). 


\section{CHAPTER III}

\section{METHODOLOGY}

\section{DESIGN AND SETTING}

A non-experimental, descriptive, correlational survey design was used for the purpose of the study. The sample consisted of 50 participants out of 100 surveyed registered nurses, currently employed in the intensive care area at a large teaching hospital in South Florida. All participants were asked to complete four surveys, which included the Perceived Stress Scale (PSS), the COPE scale, the Health-Related Hardiness Scale (HRHS), and a demographic information questionnaire. This study did not manipulate any variables.

\section{SAMPLE AND SAMPLING METHOD}

The participants for this study included a convenience sample of registered nurses employed in the intensive care units of a South Florida teaching hospital of various ages, gender, ethnic backgrounds, religious beliefs, educational levels, and years of nursing experience. The participants for this study were contacted after permission was obtained from the hospital's Institutional Review Board committee. The nurse managers of each unit were contacted and provided with an overview of the study, its purpose, and procedures to be used. All participants remained anonymous and all shifts were included. 


\section{INSTRUMENTS}

Four instruments were used for the data collection of this study. (See Appendix A). The instruments included were: (a) a demographic information questionnaire, (b) the Perceived Stress Scale (PSS) developed by Cohen, Kamarck, and Mermelstein (1983), (c) the COPE Scale developed by Carver et al. (1989), and (d) the Health-Related Hardiness Scale (HRHS) developed by Pollock (Pollock \& Duffy, 1990). Permission to use above instruments was requested and granted by their respective authors.

\section{DEMOGRAPHIC INFORMATION QUESTIONNAIRE}

The demographic information questionnaire was used to obtain information regarding the participants' age, gender, nursing education, and years of nursing experience. The subjects were also asked about the number of years of experience at their present job, schedule at work, and job classification in the clinical ladder.

\section{PERCEIVED STRESS SCALE (PSS)}

The Perceived Stress Scale (PSS) was designed to measure the degree to which situations in an individual's life are perceived to be stressful. Cohen et al. (1983) describe the advantages of using scales in the measurement of stressful events, while providing the investigator with an estimate of the increased risk for disease associated with the occurrence of easily identifiable events. The measurement procedure appears to be simple and helpful at minimizing the chance of various subjective biases in the perceptions and reporting of events (Cohen et al., 1983). Moreover, perceived stress 
scales could be used in conjunction with objective scales in order to determine whether factors such as social support, hardiness, and locus of control protect people from the effects of stressful events. The above was achieved by way of altering processes through which appraised stress resulted in physiological or behavioral disorders (Cohen et al., 1983). The items were further designed by Cohen et al. (1983) to tap the degree to which respondents found their lives unpredictable, uncontrollable, and overloading. The PSS consists of a 14-item measure of the degree to which situations in one's life are appraised as stressful. The PSS scores are obtained by reversing the scores on the seven positive items and summing up across all 14 items. Items 4,5,6,7,9,10, and 13 are the positively stated items (Cohen et al., 1983). Possible total scores for this scale ranged between 0 to 56 . Testing of this scale showed mean scores of 23.18 and 23.67 in a student sample and 25.0 in a smoking-cessation sample (males and females). Standard deviations were 7.31,7.79, and 8.00; and ranges were 6 to 50,5 to 44 , and 7 to 47 . Mean scores for females were 23.57 and 25.71 in the student samples and 25.6 in a community sample. Standard deviations were $6.79,8.42$, and 7.80 , respectively. Although the mean PSS score for females was slightly higher than the mean score for males in all three samples, this difference did not cause statistical significance in any sample. Coefficient alpha reliability for the PSS was $.84, .85$, and .86 in each of the three samples (Cohen et al., 1983).

\section{COPE SCALE}

The COPE Scale is a multi-dimensional coping inventory that assesses the different ways in which people respond to stress. This instrument was developed 
through the incorporation of 13 different scales measuring the responses mentioned above (Carver et al., 1989). The COPE scale consists of five scales that measure different aspects of problem-focused coping (active coping, planning, suppression of competing activities, restraint coping, seeking of instrumental social support). There are also five scales that measure aspects of emotion-focused coping (seeking of emotional social support, positive reinterpretation, acceptance, denial, turning to religion); and three scales that measure coping responses that are less useful (focus on and venting of emotions, behavioral disengagement, and mental disengagement). Total possible scoring of this inventory may range between 60 to 240 . Previous testing of this instrument demonstrated Cronbach's alpha reliability coefficients for each scale ranging between .45 to .92 , with one scale falling below .6. Test-retest reliability of the subscales ranged from .46 to .86 at 8 weeks and .42 to .89 at 6 weeks on a test of two samples, suggesting the relative stability of the COPE scale to measure self-reports of coping tendencies. Although the scales are not strongly interrelated, these implications support the assumption that people dealing with stress experience a relative wide range of coping impulses. The fact that these coping tendencies are separable empirically allows for the possibility of their study in separate ways (Carver et al., 1989). Moreover, correlations between the COPE scales and other instruments showed active coping and planning to be positively associated with optimism, the feeling of being able to do something about stressful situations, self-esteem, hardiness, and type A personality. Active coping was inversely correlated with trait anxiety. In contrast, denial and behavioral disengagement were positively correlated with trait anxiety and negatively correlated with optimism, the feeling of being able to do something about 
stressful situations, self-esteem, hardiness, and type A personality. The monitoring measure correlated positively with seeking instrumental social support and turning to religion, and negatively to behavioral disengagement below the .01 criterion. Overall, the COPE scales proved to be free of association with blunting, locus of control, and social desirability scale measures (Carver et al., 1989).

\section{HEALTH-RELATED HARDINESS SCALE (HRHS)}

The Health-Related Hardiness Scale was developed initially to measure the hardiness characteristic in the chronically ill (Pollock, Christian, and Sands, 1990). The use of the HRHS has further been extended to measure hardiness in both well and ill populations, as Pollock describes its application on a study of 244 adults who described themselves as healthy. This study proved the HRHS to be an appropriate measure to be used with "well" adults in health-related research. (Pollock, 1989). The HRHS was developed using the theoretical definitions of health-related control, commitment, and challenge. Pollock (1986) defined control as the sense of mastery or self-confidence needed to appraise and interpret health stressors, measured by the presence of health and locus of control towards the health stressor. Commitment was further defined as the motivation and competence to effectively cope with the threat of a health stressor. This was measured by the presence of active involvement in efforts to maintain or improve health (Pollock, 1986). Challenge or reappraisal of health stressors was then defined as a stimulating and potentially beneficial opportunity for growth, being measured by the presence of flexibility and persistence in coping with health stressors (Pollock, 1986). The initial HRHS consisted of 51 items, which were subsequently 
narrowed down to 34 items based on a six-point Likert scale. Subjects are asked to circle the extent to which they agree or disagree with each statement on the HRHS. All items are scored on a 6-point scale from $1=$ strongly disagree to $6=$ strongly agree. The scoring is then reversed for negatively worded items. Higher scores on the scale indicate greater hardiness. The 34-item HRHS measures the dimensions of challenge and commitment interrelated in 20 items, while the dimension of control is measured separately in 14 items (Pollock \& Duffy, 1990). Overall, the HRHS has demonstrated high internal consistency with a standard alpha coefficient of .91 . Previous testing of the HRHS showed Cronbach's alphas of .87 for both the 20 -item Challenge/ Commitment scale and the 14-item Control scale. Item-total correlations for all subscores and total scores exceeded .30 . Test-retest reliability at a six-month interval was .76 for the total scale, .74 for the Challenge/ Commitment subscale and .78 for the Control subscale (Pollock \& Duffy, 1990). Pollock \& Duffy (1990) further stated that parsimony of the HRHS scale was obtained by reducing the original 51 -item scale to a 34-item scale. Pollock \& Duffy (1990) further concluded that this scale had three main advantages over Kobasa' $s$ hardiness measure for health-related research: health specificity, measurement of the presence of the factors (Commitment/Challenge and Control), rather than the absence to determine hardiness and an easier scoring method.

\section{PROTECTION OF HUMAN RIGHTS}

All participants signed an informed consent after approval was obtained from the University and health care facility's Institutional Review Board. The participants were also provided with a letter explaining the purpose of the study, the anonymity of 
the subjects, and their voluntary participation. The letter explained the absence of any risks or benefits for participation in such study, the participants' right to refuse to participate and withdraw at any time from the study, and the name of contact sources should they have any questions about the study. The four instruments of data collection were included with this letter in an envelope provided to the participants. The participants remained anonymous, as their responses were assigned a code number known only by the investigator. A code number was assigned to each set of questionnaires, which were handled by the principal investigator and statistician. Data collection took place on a daily basis for a period of three weeks. The participants were informed that the results of the study were to be released in terms of group findings.

\section{DATA COLLECTION PROCEDURES}

Participant recruitment and data collection for this study took place after approval was obtained from the University and hospital's Institutional Review Board where the research study took place. The nurse managers of each unit were contacted for information about the study and permission to conduct such study a week prior to data collection. The participants for this study were approached during the week of data collection during their shifts of work duty, where they were explained about the purpose of the study. They were also provided with the envelope containing the letter explaining the study and the four instruments of data collection. Data was obtained by completion of the four questionnaires provided to each subject, who submitted these during a period of three weeks in a marked box located in each unit. Moreover, filling 
out of the four questionnaires took place on the participants' own free time, whether this was during their break time or at home.

\section{DATA ANALYSIS}

The computer program Statistical Package for the Social Sciences (SPSS) was used for analysis of the data collected. Analysis of such gathered data included the use of frequency distributions, percentages, means, and standard deviations for the demographic data, the Perceived Stress Scale, COPE Inventory, and Health-Related Hardiness Scale. Correlation procedures, including Pearson's $r$ were used to determine the correlation between the operational definitions under study. 


\section{CHAPTER IV \\ PRESENTATION OF FINDINGS}

The problem examined involved the perception and coping of critical care nurses who face a great amount of stress every day when working in a highly technical environment. In such environment, these nurses possess a very special role in the management of patients' changing complex health problems. For that reason, nurses who elect to work in such environment must possess certain personality characteristics that may enable them to cope with the various stressors of their work daily. The purpose of this study was to determine the relationship between critical care nurses' perception of stress, their ability to cope with stress, and the hardiness personality they possess while working in the critical care environment.

For the study, the SPSS Student Version 9.0 for Windows statistical package was utilized to analyze the data obtained from the following:

- A self-developed demographic questionnaire.

- The Perceived Stress Scale (PSS) developed by Cohen, Kamarck, and Mermelstein (1983).

- The COPE inventory developed by Carver, Scheier, and Weintraub (1989).

- The modified Health-Related Hardiness Scale (HRHS) developed by Pollock (Pollock \& Duffy, 1990).

The sampling approach used a convenience sample of registered nurses employed in the intensive care units and progressive care units of a South Florida teaching hospital. The sample size for the study included 50 participants. 


\section{DATA PROCESSING}

The data collected consisted of survey instruments on a Likert-type scale to

measure the variables that were examined in this study. The results (i. e., the final score

of each measure of variable) of each of these surveys had to be pre-processed using an

Excel spreadsheet before they could be modeled using the SPSS Student Version 9.0 for

Windows statistical package.

\begin{tabular}{|c|c|c|c|c|c|c|c|c|c|c|c|c|c|c|c|c|c|c|c|}
\hline & A & $B$ & $\mathrm{C}$ & D & $E$ & $F$ & $G$ & $\mathrm{H}$ & 1 & $J$ & $K$ & $L$ & $M$ & $N$ & 0 & $P$ & $Q$ & $\mathrm{R}$ & 5 \\
\hline 1 & CASE & 1 & 2 & 3 & 4 & 5 & 6 & 7 & 8 & 9 & 10 & 11 & 12 & 13 & 14 & 15 & 16 & 17 & 18 \\
\hline 2 & 1 & 1 & 1 & 4 & 4 & 3 & 1 & 4 & 3 & 4 & 3 & 4 & 1 & 2 & 4 & 1 & 1 & 4 & 4 \\
\hline 3 & 2 & 4 & 4 & 2 & 4 & 4 & 1 & 4 & 1 & 2 & 3 & 4 & 2 & 3 & 4 & 4 & 3 & 2 & 4 \\
\hline 4 & 3 & 4 & 3 & 2 & 2 & 3 & 1 & 1 & 4 & 2 & 2 & 4 & 2 & 3 & 3 & 2 & 2 & 3 & 1 \\
\hline 5 & 4 & 4 & 3 & 2 & 4 & 3 & 2 & 4 & 3 & 3 & 3 & 4 & 2 & 3 & 3 & 2 & 3 & 3 & 4 \\
\hline 6 & 5 & 3 & 4 & 2 & 3 & 2 & 2 & 2 & 1 & 1 & 3 & 2 & 1 & 2 & 3 & 2 & 2 & 2 & 2 \\
\hline 7 & 6 & 4 & 2 & 2 & 3 & 2 & 2 & 4 & 2 & 1 & 3 & 2 & 1 & 1 & 3 & 3 & 1 & 2 & 4 \\
\hline$\theta$ & 7 & 4 & 4 & 1 & 1 & 4 & 4 & 4 & 4 & 2 & 2 & 2 & 1 & 4 & 4 & 4 & 2 & 2 & 4 \\
\hline 9 & 8 & 4 & 3 & 3 & 2 & 4 & 2 & 4 & 2 & 1 & 2 & 3 & 1 & 3 & 3 & 2 & 2 & 2 & 4 \\
\hline 10 & 9 & 2 & 3 & 2 & 2 & 3 & 1 & 2 & 1 & 1 & 2 & 2 & 1 & 2 & 2 & 1 & 2 & 3 & 2 \\
\hline 11 & 10 & 4 & 4 & 2 & 1 & 3 & 2 & 4 & 3 & 3 & 4 & 2 & 1 & 3 & 4 & 2 & 4 & 3 & 4 \\
\hline 12 & 11 & 4 & 4 & 1 & 1 & 1 & 1 & 4 & 4 & 1 & 4 & 1 & 1 & 2 & 1 & 4 & 1 & 1 & 4 \\
\hline 13 & 12 & 4 & 3 & 2 & 3 & 3 & & & & & & & & & & & & & \\
\hline 14 & 13 & 4 & 4 & 2 & 1 & 4 & 2 & 3 & 1 & 2 & 3 & 1 & 1 & 2 & 2 & 2 & 1 & 3 & 3 \\
\hline 15 & 14 & 3 & 3 & 2 & 2 & 3 & 1 & 4 & 3 & 1 & 2 & 3 & 1 & 2 & 4 & 3 & 2 & 3 & 4 \\
\hline 16 & 15 & 4 & 4 & 3 & 3 & 4 & 4 & $\overline{4}$ & 3 & 1 & 4 & 2 & 1 & 2 & 2 & 2 & 1 & 3 & 4 \\
\hline 17 & 16 & 4 & 4 & 4 & 4 & 4 & 4 & $\overline{4}$ & 4 & 4 & 3 & 4 & 1 & 4 & 4 & 3 & 4 & 4 & 4 \\
\hline 18 & 17 & 3 & 3 & 3 & 4 & 3 & 2 & 4 & 4 & 2 & 4 & 4 & 1 & 3 & 4 & 3 & 2 & 4 & 4 \\
\hline 19 & 18 & 2 & 3 & 4 & 3 & 3 & 3 & 3 & 2 & 1 & 1 & 3 & 1 & 3 & 3 & 2 & 2 & 1 & 2 \\
\hline 20 & 19 & 4 & 3 & 3 & 4 & 4 & 1 & 3 & 3 & 1 & 2 & 4 & 1 & 3 & 3 & 2 & 2 & 3 & 3 \\
\hline 21 & 20 & 4 & 4 & 2 & 2 & 4 & 1 & 1 & 4 & 2 & 2 & 2 & 2 & 3 & 2 & 1 & 1 & 1 & 1 \\
\hline 22 & 21 & 4 & 4 & 2 & 4 & 3 & 3 & 4 & 4 & 4 & 4 & 4 & 2 & 3 & 4 & 4 & 4 & 2 & 4 \\
\hline 23 & 22 & 4 & 4 & 1 & 3 & 4 & 1 & 4 & 4 & 9 & 4 & 3 & 1 & 3 & 4 & 4 & 1 & 4 & 4 \\
\hline 24 & 23 & 4 & 3 & 2 & 3 & 4 & 1 & 4 & 1 & 1 & 3 & 4 & 1 & 1 & 4 & 3 & 2 & 3 & 4 \\
\hline 25 & 24 & 4 & 1 & 2 & 3 & 4 & 1 & 4 & 2 & 1 & 2 & 3 & 1 & 3 & 3 & 3 & 1 & 3 & 4 \\
\hline 26 & 25 & 3 & 3 & 4 & 4 & 3 & 2 & 3 & 2 & 1 & 3 & 4 & 1 & 2 & 3 & 2 & 1 & 2 & 3 \\
\hline 27 & 26 & 4 & 1 & 2 & 2 & 4 & 2 & 1 & 4 & 1 & 2 & 1 & 1 & 2 & 2 & 3 & 3 & 2 & 1 \\
\hline 28 & 27 & 4 & 3 & 3 & 3 & 2 & 3 & 4 & 4 & 2 & 3 & 4 & 1 & 2 & 3 & 3 & 3 & 3 & 4 \\
\hline 29 & 28 & 4 & 3 & 2 & 2 & 4 & 1 & $\overline{4}$ & 4 & 2 & 4 & 4 & 1 & 4 & 4 & 4 & 4 & 4 & 4 \\
\hline 30 & 29 & 3 & 4 & 2 & 2 & 3 & 1 & 3 & 4 & 1 & 2 & 2 & 1 & 3 & 2 & 4 & 3 & 2 & 3 \\
\hline 31 & 30 & 3 & 4 & 4 & 3 & 3 & 1 & 4 & 4 & 1 & 1 & 4 & 1 & 3 & 4 & 3 & 1 & 3 & 4 \\
\hline 32 & 31 & 3 & 2 & 1 & 2 & 3 & 2 & 2 & $\overline{4}$ & 2 & 2 & 2 & 1 & 2 & 2 & 2 & 2 & 2 & 2 \\
\hline 33 & 32 & 4 & 4 & 2 & 2 & 4 & 2 & 3 & 3 & 1 & 2 & 2 & 1 & 2 & 2 & 2 & 1 & 2 & 3 \\
\hline
\end{tabular}

Figure 1. Sample Excel Spreadsheet Data Processing Entry for the COPE Scale. 
Figure 1 shows a sample of the data entry processing entry results for the COPE

scale. As a general rule, since the final score for each processed survey would be used for the statistical modeling of the study, incomplete surveys were not included. The results of the analysis would be skewed if incomplete surveys were included.

\section{PERCEIVED STRESS SCALE (PSS) DATA PROCESSING}

The PSS measured the degree to which situations in the respondent's life were appraised as stressful. The PSS score was obtained by reversing the scores on the seven positive items, e. g., $0=4,1=3,2=2$, etc., and then summing across all 14 items. Items $4,5,6,7,9,10$, and 13 of the PSS survey were positively stated items.

\section{COPE SCALE DATA PROCESSING}

The COPE Inventory measured how people responded when they confronted difficult or stressful events in their lives. The survey consisted of 61 items on a fourpoint Likert-type scale. The COPE score was obtained by summing across all of the 61 items.

\section{HEALTH-RELATED HARDINESS SCALE (HRHS) DATA PROCESSING}

The HRSS was developed to measure the hardiness construct in health-related research. The version used for the study contained 34 items on a six-point Likert-type scale. Scores for the total HRHS could range from 34 to 204 with high scores indicating presence of hardiness. The HRSS score was obtained by reversing the scores on the 19 negative items, e. g., $1=6,2=5,3=4$, etc., and then summing across all 34 
items. Items $3,4,5,9,10,11,13,15,16,17,19,20,21,22,23,24,25,26$, and 34 of the HRHS survey were negatively stated items.

\section{STATISTICAL MODELING}

After processing the data using Excel, the results were imported to the SPSS Student Version 9.0 for Windows statistical package. Incomplete surveys were not included in the study and were classified as missing data for the statistical analysis. Dimensions of each survey, if they existed, were not considered and included in the study. The processed total result of each of the survey were the only ones considered. Figure 2 below shows a representation of the modeling done in SPSS.

Missing data are represented as blank entries for the statistical model. These types of indications are necessary to correctly represent the analysis using the SPSS Student Version 9.0 for Windows statistical package. 
Q

\begin{tabular}{|c|c|c|c|c|c|c|c|c|c|c|}
\hline \multicolumn{11}{|c|}{ 16:jclass } \\
\hline & age & gender & educ & Job & nurse & sched & Jciass & cope & stress & hardy \\
\hline 1 & 36 to 40 & Female & M. S. N. & 11 to 15 & 11 to 15 & Day Shitt & PNI & 173 & . & 167 \\
\hline 2 & 31 to 35 & Female & A D. N. & 1 to 5 & 1 to 5 & Evening Shift & PN II & 175 & & 164 \\
\hline 3 & 26 to 30 & Female & A D. N. & 1 to 5 & 6 to 10 & Night Shift & Per Diem & 151 & 19 & 157 \\
\hline 4 & 31 to 35 & Male & B. S. N. & 1 to 5 & 6 to 10 & Day Shitt & PN III & 174 & 26 & 145 \\
\hline 5 & 26 to 30 & Male & B. S. N. & 1 to 5 & 1 to 5 & Evening Shift & PN II & 128 & 23 & 168 \\
\hline 6 & 26 to 30 & Female & A.D. N. & 1 to 5 & 6 to 10 & Day Shitt & $P N \mid I I$ & 127 & 25 & 172 \\
\hline 7 & 41 to 45 & Female & B. S. N. & 16 to 20 & 16 to 20 & Evening Shith & PNI & 161 & . & 147 \\
\hline 8 & 46 to 50 & Female & B. S. N. & 21 to 25 & 21 to 25 & Night Shift & PNI & 156 & 24 & 175 \\
\hline 9 & 46 to 50 & Female & B. S. N. & 21 to 25 & 26 to 30 & Evening Shift & PNI & 127 & 30 & 169 \\
\hline 10 & 41 to 45 & Female & B. S. N. & 16 to 20 & 21 to 25 & Evening Shiff & PNI & 177 & 23 & 179 \\
\hline 11 & 26 to 30 & Female & B. S. N. & 1 to 5 & 6 to 10 & Day Shift & PNI & 146 & 16 & 183 \\
\hline 12 & 36 to 40 & Femaie & Diploma & 6 to 10 & 16 to 20 & Day Shift & PNI & . & & 184 \\
\hline 13 & 46 to 50 & Female & B. S. N. & 16 to 20 & 21 to 25 & Evening Shift & PNI & 144 & . & 174 \\
\hline 14 & 46 to 50 & Femais & B. S. N. & 21 to 25 & 21 to 25 & Day Shift & PNI & 159 & 12 & 161 \\
\hline 15 & 26 to 30 & Female & Diploma & 6 to 10 & 6 to 10 & Day Shitt & PNI & 163 & 28 & 170 \\
\hline 16 & 41 to 45 & Female & B. S. N. & 16 to 20 & 21 to 25 & Day Shift & PNI & 221 & 17 & 189 \\
\hline 17 & 41 to 45 & Female & B. S. N. & 21 to 25 & 21 to 25 & Night Shift & PNI & 194 & 26 & 179 \\
\hline 18 & 36 to 40 & Female & B. S. N. & 1 to 5 & 11 to 15 & Day Shift & PNI & 139 & 23 & 189 \\
\hline 19 & 31 to 35 & Male & B. S. N. & 1 to 5 & 1 to 5 & Evening Shift & Per Diem & 164 & 20 & 151 \\
\hline 20 & 26 to 30 & Female & A. D. N. & 1 to 5 & 6 to 10 & Erening Shift & PN III & 134 & . & 184 \\
\hline
\end{tabular}

Figure 2. Statistical Modeling Using SPSS.

\section{DEMOGRAPHIC RESULTS}

The participants for the convenience sample consisted of registered nurses employed in the intensive care units and progressive care units of a South Florida teaching hospital. The sample consisted of fifty (50) registered nurses whose participation was entirely voluntary and their anonymity maintained. There was no duplication of the sample membership. All of the nurses in this study were of various levels of experience. 
The most predominant age categories were from the age groups of 41 to 45 years and 46 to 50 years of age. The complete frequency distribution of the respondents' age is shown in Table 1.

\begin{tabular}{|c|c|c|c|c|}
\hline Age & Frequency & Percent & $\begin{array}{c}\text { Valid } \\
\text { Percent }\end{array}$ & $\begin{array}{c}\text { Cumulative } \\
\text { Percent }\end{array}$ \\
\hline 20 to 25 & 1 & 2.0 & 2.0 & 2.0 \\
\hline 26 to 30 & 7 & 14.0 & 14.0 & 16.0 \\
\hline 31 to 35 & 7 & 14.0 & 14.0 & 30.0 \\
\hline 36 to 40 & 4 & 8.0 & 8.0 & 38.0 \\
\hline 41 to 45 & 16 & 32.0 & 32.0 & 70.0 \\
\hline 46 to 50 & 11 & 22.0 & 22.0 & 92.0 \\
\hline 51 to 55 & 2 & 4.0 & 4.0 & 96.0 \\
\hline 56 to 60 & 1 & 2.0 & 2.0 & 98.0 \\
\hline $\begin{array}{c}61 \text { or } \\
\text { older }\end{array}$ & 1 & 2.0 & 2.0 & 100.0 \\
\hline Total & 50 & 100.0 & 100.0 & \\
\hline
\end{tabular}

Table 1. Frequency Distribution of Respondent's Age.

There were 46 females and four males that participated in this study. The complete frequency distribution of the respondents' gender is shown in Table 2.

\begin{tabular}{|c|c|c|c|c|}
\hline Gender & Frequency & Percent & $\begin{array}{c}\text { Valid } \\
\text { Percent }\end{array}$ & $\begin{array}{c}\text { Cumulative } \\
\text { Percent }\end{array}$ \\
\hline Male & 4 & 8.0 & 8.0 & 8.0 \\
\hline Female & 46 & 92.0 & 92.0 & 100.0 \\
\hline Total & 50 & 100.0 & 100.0 & \\
\hline
\end{tabular}

Table 2. Frequency Distribution of Respondent's Gender. 
Most of the respondents indicated that they had completed their Bachelor of Science in Nursing (27 out of 50 respondents). The frequency distribution of the participants' response for their highest level of education is shown in Table 3.

\begin{tabular}{|c|c|c|c|c|}
\hline $\begin{array}{c}\text { Highest Level of } \\
\text { Education }\end{array}$ & Frequency & Percent & $\begin{array}{c}\text { Valid } \\
\text { Percent }\end{array}$ & $\begin{array}{c}\text { Cumulative } \\
\text { Percent }\end{array}$ \\
\hline Diploma & 5 & 10.0 & 10.0 & 10.0 \\
\hline A. D. N. & 9 & 18.0 & 18.0 & 28.0 \\
\hline B. S. N. & 27 & 54.0 & 54.0 & 82.0 \\
\hline $\begin{array}{c}\text { B. S. (Another } \\
\text { Field) }\end{array}$ & 3 & 6.0 & 6.0 & 88.0 \\
\hline M. S. N. & 5 & 10.0 & 10.0 & 98.0 \\
\hline $\begin{array}{c}\text { M. S. (Another } \\
\text { Field) }\end{array}$ & 1 & 2.0 & 2.0 & 100.0 \\
\hline Total & 50 & 100.0 & 100.0 & \\
\hline
\end{tabular}

Table 3. Frequency Distribution of Respondent's Highest Level of Education.

When the participants were surveyed as to their number of years in their present job, the responses revealed no dominating category. The distribution showed that the most dominating categories were of 1 to 5 years, 16 to 20 years, and 21 to 25 years of being in their current job. Each of the categories mentioned had a frequency of 12 respondents each. The frequency distribution is summarized in Table 4.

\begin{tabular}{|c|c|c|c|c|}
\hline $\begin{array}{c}\text { Number of } \\
\text { Years in } \\
\text { Present Job }\end{array}$ & Frequency & Percent & $\begin{array}{c}\text { Valid } \\
\text { Percent }\end{array}$ & $\begin{array}{c}\text { Cumulative } \\
\text { Percent }\end{array}$ \\
\hline 1 to 5 & 12 & 24.0 & 24.0 & 24.0 \\
\hline 6 to 10 & 11 & 22.0 & 22.0 & 46.0 \\
\hline 11 to 15 & 2 & 4.0 & 4.0 & 50.0 \\
\hline 16 to 20 & 12 & 24.0 & 24.0 & 74.0 \\
\hline 21 to 25 & 12 & 24.0 & 24.0 & 98.0 \\
\hline 26 to 30 & 1 & 2.0 & 2.0 & 100.0 \\
\hline Total & 50 & 100.0 & 100.0 & \\
\hline
\end{tabular}

Table 4. Frequency Distribution of Respondent's Number of Years in Present Job. 
Most of the respondents ( 16 out of 50) had 21 to 25 years of nursing experience.

The categories of 6 to 10 years and 16 to 20 years of nursing experience were not that far off. The category of 6 to 10 years had 14 responses and the category of 16 to 20 years had 10 responses. The frequency distribution is summarized in Table 5.

\begin{tabular}{|c|c|c|c|c|}
\hline $\begin{array}{c}\text { Number of Years } \\
\text { of Nursing } \\
\text { Experience }\end{array}$ & Frequency & Percent & $\begin{array}{c}\text { Valid } \\
\text { Percent }\end{array}$ & $\begin{array}{c}\text { Cumulative } \\
\text { Percent }\end{array}$ \\
\hline 1 to 5 & 4 & 8.0 & 8.0 & 8.0 \\
\hline 6 to 10 & 14 & 28.0 & 28.0 & 36.0 \\
\hline 11 to 15 & 3 & 6.0 & 6.0 & 42.0 \\
\hline 16 to 20 & 10 & 20.0 & 20.0 & 62.0 \\
\hline 21 to 25 & 16 & 32.0 & 32.0 & 94.0 \\
\hline 26 to 30 & 3 & 6.0 & 6.0 & 100.0 \\
\hline Total & 50 & 100.0 & 100.0 & \\
\hline
\end{tabular}

Table 5. Frequency Distribution of Respondent's Number of Years of Nursing Experience.

When asked about the respondents work schedule, the responses were basically split between day shift (22 respondents) and evening shift (21 respondents) work schedules. The frequency distribution is summarized in Table 6 .

\begin{tabular}{|c|c|c|c|c|}
\hline $\begin{array}{c}\text { Work } \\
\text { Schedule }\end{array}$ & Frequency & Percent & $\begin{array}{c}\text { Valid } \\
\text { Percent }\end{array}$ & $\begin{array}{c}\text { Cumulative } \\
\text { Percent }\end{array}$ \\
\hline Day Shift & 22 & 44.0 & 44.0 & 44.0 \\
\hline $\begin{array}{c}\text { Evening } \\
\text { Shift }\end{array}$ & 21 & 42.0 & 42.0 & 86.0 \\
\hline Night Shift & 7 & 14.0 & 14.0 & 100.0 \\
\hline Total & 50 & 100.0 & 100.0 & \\
\hline
\end{tabular}

Table 6. Frequency Distribution of Respondent's Work Schedule. 
Most of the respondents were of the PN I level (29 out of 50 respondents)

followed by respondents of the PN II level when asked about their respective job classifications. The frequency distribution is summarized in Table 7.

\begin{tabular}{|c|c|c|c|c|}
\hline $\begin{array}{c}\text { Job } \\
\text { Classification }\end{array}$ & Frequency & Percent & $\begin{array}{c}\text { Valid } \\
\text { Percent }\end{array}$ & $\begin{array}{c}\text { Cumulative } \\
\text { Percent }\end{array}$ \\
\hline PN I & 29 & 58.0 & 58.0 & 58.0 \\
\hline PN II & 12 & 24.0 & 24.0 & 82.0 \\
\hline PN III & 4 & 8.0 & 8.0 & 90.0 \\
\hline Per Diem & 5 & 10.0 & 10.0 & 100.0 \\
\hline Total & 50 & 100.0 & 100.0 & \\
\hline
\end{tabular}

Table 7. Frequency Distribution of Respondent's Job Classification.

\section{SURVEY RESULTS}

The Perceived Stress Scale (PSS) measured the degree to which situations in the respondent's life were appraised as stressful. There were only 37 (out of possible 50) valid surveys in the study since some of the surveys were not completely filled out by the respondents. The processed PSS scores ranged from 12 to 35 with a mean of 23.84 and a standard deviation of 5.44. The PSS score histogram shown in Figure 3 shows a fairly normal distribution.

The COPE Inventory measured how people responded when they confronted difficult or stressful events in their lives. There were 48 (out of possible 50) valid surveys since two of the surveys were not completely filled out by the respondents. The processed COPE Inventory scores ranged from 124 to 221 with a mean of 156.98 and a standard deviation of 20.53. The COPE Inventory score histogram shown in Figure 4 shows a fairly negatively skewed normal distribution. 
The Health-Related Hardiness Scale (HRSS) was developed to measure the hardiness construct in health-related research. There were 49 (out of possible 50) valid surveys since one survey was not completely filled out by a respondent. The processed HRSS scores ranged from 139 to 199 with a mean of 173.71 and a standard deviation of 14.11. The HRSS score histogram shown in Figure 5 shows a fairly positively skewed normal distribution.

The survey statistical summary of the results is shown in Table 8 .

\begin{tabular}{|c|c|c|c|c|c|}
\hline Survey & $\mathrm{N}$ & Minimum & Maximum & Mean & $\begin{array}{c}\text { Std. } \\
\text { Deviation }\end{array}$ \\
\hline PSS Score & 37 & 12 & 35 & 23.84 & 5.44 \\
\hline $\begin{array}{c}\text { COPE } \\
\text { Inventory Score }\end{array}$ & 48 & 124 & 221 & 156.98 & 20.53 \\
\hline HRHS & 49 & 139 & 199 & 173.71 & 14.11 \\
\hline
\end{tabular}

Table 8. Survey Statistical Summary of Results. 


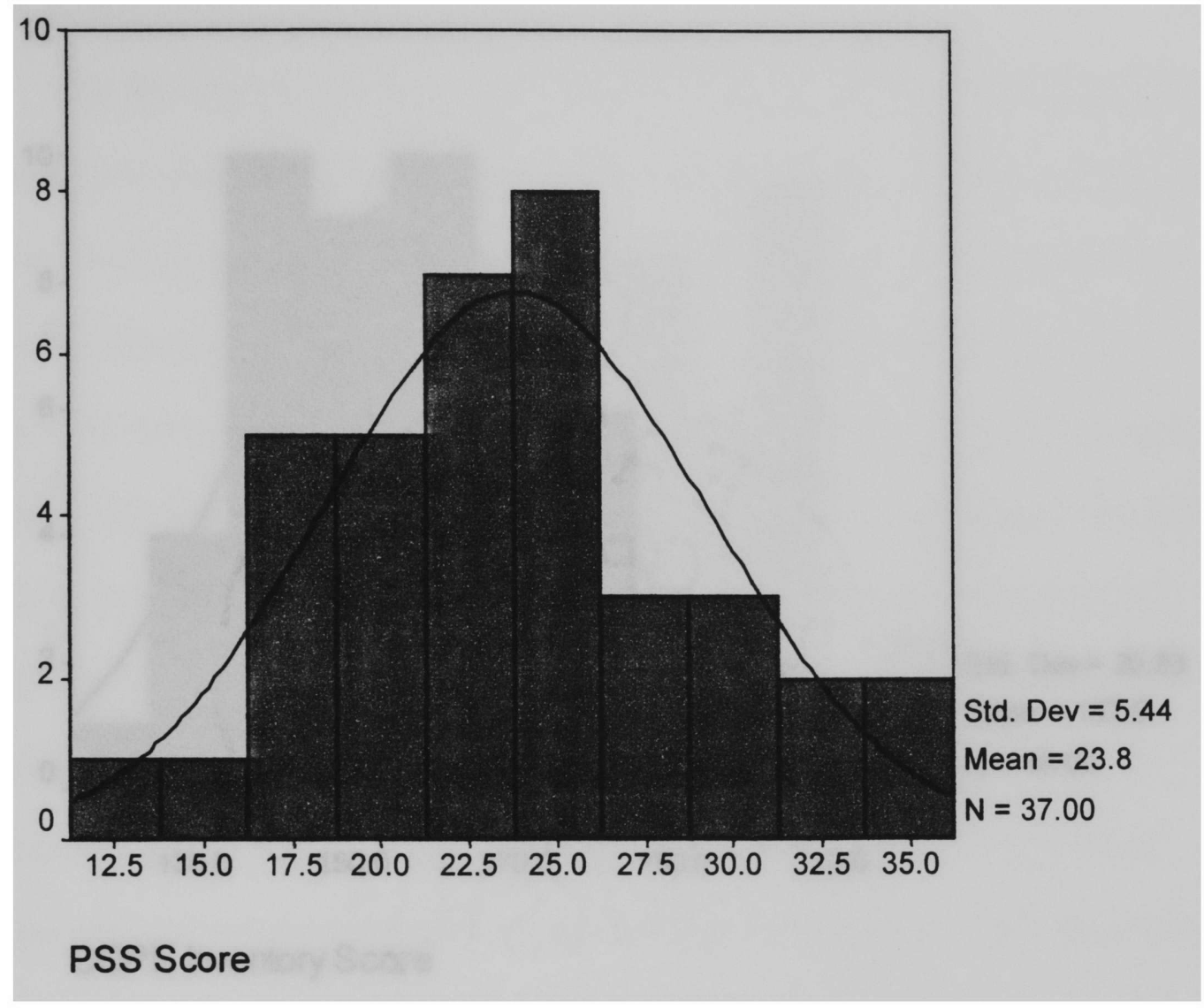

Figure 3. PSS Score Histogram. 


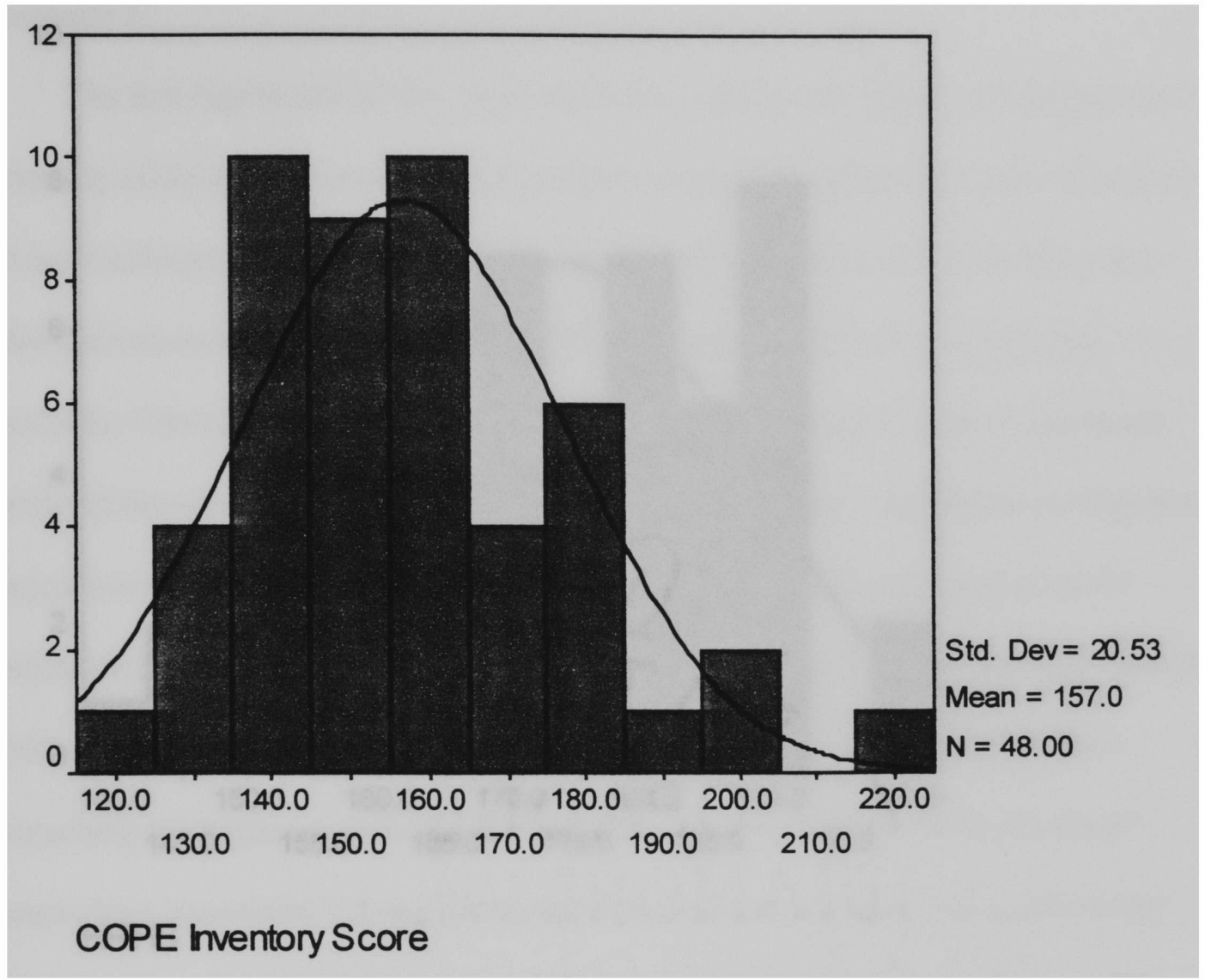

Figure 4. COPE Inventory Score Histogram. 


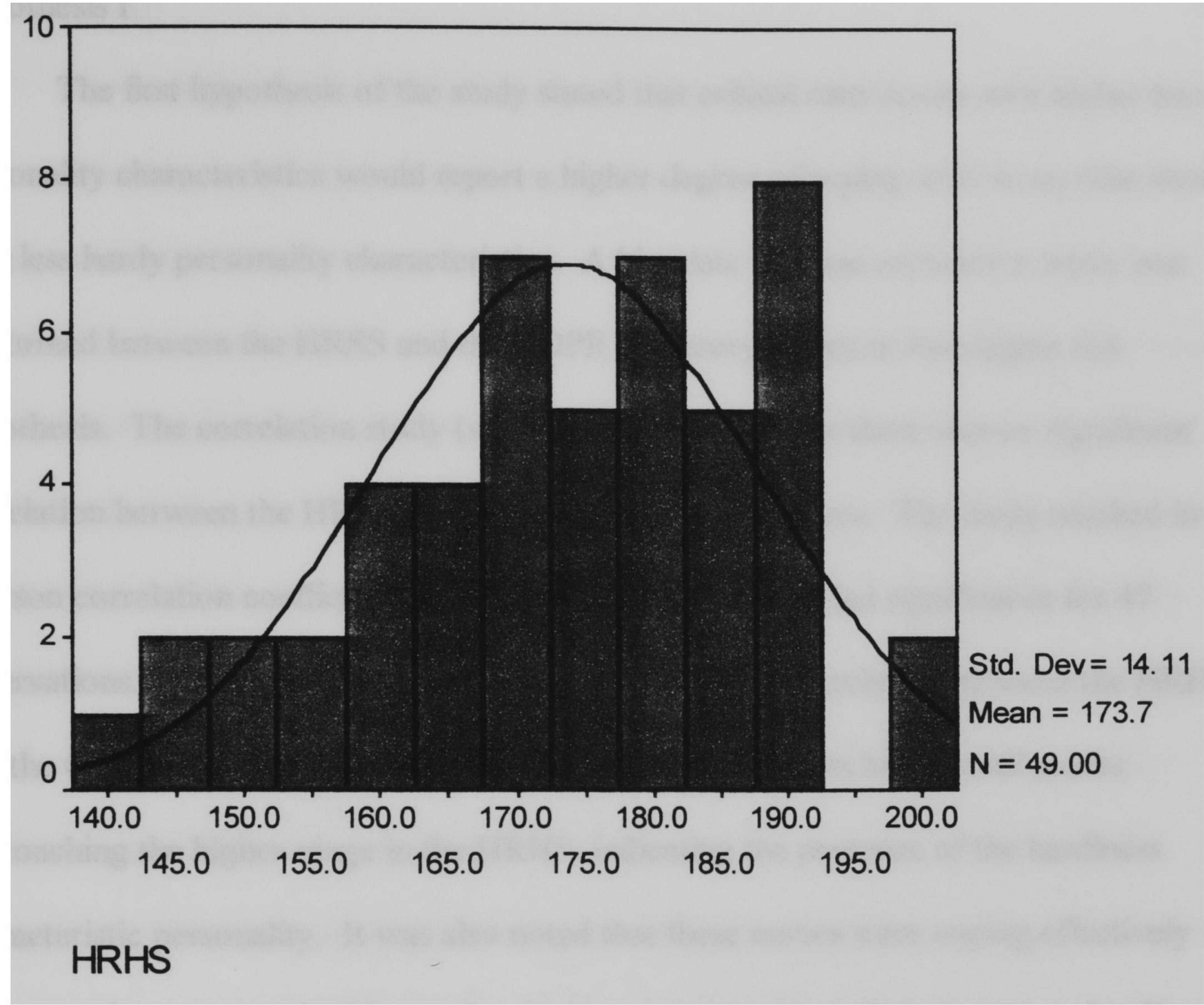

Figure 5. HRSS Score Histogram.

\section{HYPOTHESES RESULTS}

This study consisted of three hypotheses that needed to be investigated. The SPSS Student Version 9.0 for Windows statistical package was used to analyze each of the three hypotheses. Correlation analysis was performed for each study. 
Hypothesis I

The first hypothesis of the study stated that critical care nurses with higher hardy personality characteristics would report a higher degree of coping with stress than those with less hardy personality characteristics. A bivariate Pearson correlation study was performed between the HRSS and the COPE Inventory scores to investigate this hypothesis. The correlation study (see Table 9) revealed that there was no significant correlation between the HRSS and the COPE Inventory scores. The study resulted in a Pearson correlation coefficient of 0.092 with a 0.539 two-tailed significance for 47 observations. Although there seemed to be no statistical correlation between the HRHS and the COPE Inventory, it was noted that the 49 participants had overall scores approaching the higher range in the HRHS, indicating the presence of the hardiness characteristic personality. It was also noted that these nurses were coping effectively with stressful events by looking at the minimum, maximum, and mean scores, heading towards the upper range of possible scores on the COPE Inventory $(60-240)$.

\begin{tabular}{|c|c|c|c|}
\cline { 3 - 4 } \multicolumn{2}{c|}{} & $\begin{array}{c}\text { COPE Inventory } \\
\text { Score }\end{array}$ & HRHS \\
\hline \multirow{3}{*}{$\begin{array}{c}\text { COPE Inventory } \\
\text { Score }\end{array}$} & $\begin{array}{c}\text { Pearson } \\
\text { Correlation }\end{array}$ & 1.000 & .092 \\
\cline { 2 - 4 } & Sig. (2-tailed) &. & .539 \\
\cline { 2 - 4 } & $\mathrm{N}$ & 48 & 47 \\
\hline \multirow{3}{*}{ HRHS } & $\begin{array}{c}\text { Pearson } \\
\text { Correlation }\end{array}$ & .092 & 1.000 \\
\cline { 2 - 4 } & Sig. (2-tailed) & .539 &. \\
\cline { 2 - 4 } & $\mathrm{N}$ & 47 & 49 \\
\hline
\end{tabular}

Table 9. Bivariate Pearson Correlation Study for Hypothesis I. 
Hypothesis II:

The second hypothesis of the study stated that critical care nurses with higher degree of coping would report less perception of stress from those with lesser degree of coping. A bivariate Pearson correlation study was performed between the PSS and the COPE Inventory scores to investigate this hypothesis. The correlation study (see Table 10) revealed that there was no statistically significant correlation between the PSS and the COPE Inventory scores. The study resulted in a Pearson correlation coefficient of 0.062 with a 0.717 two-tailed significance for 37 observations. Although the results obtained did not reveal significant correlations to support hypothesis II, it was noted that these critical care nurses had moderate perception of stress by looking at their minimum, maximum, and mean scores within the possible scores for the Perceived Stress Scale. Therefore, analysis of the results obtained revealed the participants were able to cope moderately with stressful events regardless of their moderate to high perception of stress.

\begin{tabular}{|c|c|c|c|}
\hline & & $\begin{array}{l}\text { COPE Inventory } \\
\text { Score }\end{array}$ & PSS Score \\
\hline \multirow[t]{3}{*}{$\begin{array}{l}\text { COPE Inventory } \\
\text { Score }\end{array}$} & $\begin{array}{c}\text { Pearson } \\
\text { Correlation }\end{array}$ & 1.000 & -.062 \\
\hline & Sig. (2-tailed) & & .717 \\
\hline & $\mathrm{N}$ & 48 & 37 \\
\hline \multirow[t]{3}{*}{ PSS Score } & $\begin{array}{c}\text { Pearson } \\
\text { Correlation }\end{array}$ & -.062 & 1.000 \\
\hline & Sig. (2-tailed) & .717 & \\
\hline & $\overline{\mathrm{N}}$ & 37 & 37 \\
\hline
\end{tabular}

Table 10. Bivariate Pearson Correlation Study for Hypothesis II. 
The third hypothesis of the study stated that critical care nurses with higher hardy personality traits would report a lesser perception of stress from those with lesser hardy personality traits. A bivariate Pearson correlation study was performed between the HRSS and the PSS scores to investigate this hypothesis. The correlation study (see Table 11) revealed that there was no statistically significant correlation between the HRSS and the PSS scores. The study resulted in a Pearson correlation coefficient of 0.189 with a 0.263 two-tailed significance for 37 observations. However, it was noted that these critical care nurses had moderate perception of stress in their lives and possessed the presence of hardiness personality characteristics evidenced by the high scores in the Health-Related Hardiness Scale, which may have assisted them in their coping with stress.

\begin{tabular}{|c|c|c|c|}
\cline { 3 - 4 } \multicolumn{2}{c|}{} & PSS Score & HRHS \\
\hline PSS Score & $\begin{array}{c}\text { Pearson } \\
\text { Correlation }\end{array}$ & 1.000 & -.189 \\
\cline { 2 - 4 } & Sig. (2-tailed) &. & .263 \\
\cline { 2 - 4 } & $\mathrm{N}$ & 37 & 37 \\
\hline HRHS & $\begin{array}{c}\text { Pearson } \\
\text { Correlation }\end{array}$ & -.189 & 1.000 \\
\cline { 2 - 4 } & Sig. (2-tailed) & .263 &. \\
\cline { 2 - 4 } & $\mathrm{N}$ & 37 & 49 \\
\hline
\end{tabular}

Table 11. Bivariate Pearson Correlation Study for Hypothesis III. 


\section{CHAPTER V}

\section{DISCUSSION, CONCLUSION, IMPLICATIONS, LIMITATIONS, AND}

\section{RECOMMENDATIONS}

\section{DISCUSSION}

The data collected from the 50 critical care nurses who participated in this study provided valuable information that may have greater contributions towards the body knowledge of nursing. Although the results did not provide statistical significance to support the hypotheses under study, they provided an insight into the critical care nurses' perception of stress, coping with stress, and personality hardiness characteristic.

Findings of this study revealed that critical care nurses do possess the presence of hardiness personality characteristics. In fact, the scores obtained revealed that these nurses' hardiness levels directed towards the higher end of the scale, meaning that they had higher hardiness personality traits. Moreover, these nurses were able to cope effectively with the stress in their lives being evidence by the scores located in the middle to the higher end of the possible scores for the COPE Scale. A previous study conducted by Pollock (1986) involving the correlation among physiological adaptation, psychological adaptation, and hardiness personality of 60 individuals with insulindependent diabetes mellitus, hypertension, and rheumatic arthritis identified no significant correlation among hardiness, physiological adaptation, or psychological adaptation among individuals coping with rheumatoid arthritis. In that study, demographic variables such as gender and social status presented significant correlation to psychological and physiological adaptation, and the presence of hardiness (Pollock, 1986). 
Second, the results of this study showed that the participants were able to cope effectively with stressful events regardless of how moderate their perception of stress was. Significant variables that may have influenced on the nurses' perception of stress, coping, and the presence of high hardiness personality characteristic were also noted. One of the findings noted was the predominance of the respondents' age, ranging from 41 to 45 and 46 to 50 years of age. Such results pose some questions as to whether aging, maturity, and the experience that comes along with them may play a key role in the individual's perception and coping with stress, and hardiness personality. These findings also appear to be significant in terms of the aging of the nursing workforce, particularly in the critical care setting. These results pose some questions as to whether the age of the nurses may play a role into their choosing the critical care environment for their work setting.

Findings of this study noted that there was the predominance of female nurses (92\%) over male nurses when looking at the nursing population in the critical care environment. This variable may provide some future implications for research as to whether there may be any differences in the individuals' perception and coping with stress. Moreover, analysis of the results obtained revealed that $54 \%$ of the respondents had completed their Bachelor of Science in Nursing. This finding appears to be significant, especially when it has been noted in previous studies that the current RN workforce includes $27 \%$ with diploma, $32 \%$ with $\mathrm{ADs}$, $31 \%$ with $\mathrm{BSNs}$, and $10 \%$ with master's or $\mathrm{PhD}$ degrees (Bednash, 2000). Possible reasons to explain these findings may include the fact that the participants were of various ethnicities, mostly Filipino nurses, who may have completed their Bachelor degree in their native country. 
Another factor that may be considered as influential to the variables under study could include the fact that these nurses have been working between 1 to 5,16 to 20 , and 21 to 25 years in their present job. These findings pose some questions as to whether all those years of experience in their present job setting may be influential to the critical care nurses' sense of control, commitment to their work setting, and personality hardiness. These findings also provide an avenue for investigation of the factors that encourage these nurses to stay in the same setting for an extensive length of time; and whether these same factors have helped them cope with stress throughout these years. Analysis of such factors may provide great input to the issue of nursing retention, especially at a time when nursing is experiencing a critical shortage. Possible reasons to explain the above may include the nurses' sense of belonging towards their work environment dependent on the interpersonal relationships among coworkers (WinterCollins \& McDaniel, 2000). A study by Hagerty and Patusky (as cited in WinterCollins \& McDaniel, 2000) reported the importance of belonging for psychological and physical well being. Another factor to be taken into consideration could include the degree of job satisfaction these nurses may possess that may encourage them to stay in one health care institution for so many years. Previous literature has noted job satisfaction to be an important factor because of its inverse relationship with turnover. Employee satisfaction has also been noted as beneficial to the patients and nursing units (Winter-Collins \& McDaniel, 2000). Could these factors and the length of the critical care nurses' stay in their work setting be found in other clinical facilities?

Furthermore, findings revealed that $32 \%$ of the participants had between 21 to 25 years of nursing experience. This should be another variable to consider as 
influential in the nurses' coping with stress and hardiness personality. The majority of the participants worked the day or evening shift schedules. This variable pose some questions to the principal investigator as to whether other factors, such as length of work schedule (8-hour shift vs. 12-hour shift vs. 16-hour shift) may play a role in the nurses' perception and coping with stress. Other questions posed related to the small amount of participants from the night shift. Possible reasons to explain the above may include several factors that may have prevented them from answering the surveys, such as family commitments at home, busier schedules at work, lack of sleep, as well as the length of the surveys.

Within the demographic questionnaire, the job classification of the respondents' was included. The term per Diem was denoted for agency nurses that may work on an as needed basis. The term PNIII was considered for the staff nurses who function at the basic starting level. The term PNII was considered for the staff nurses who function at an intermediate level and have more experience than a PNIII nurse. The term PNI was considered for the staff nurses who function at a more advanced and independent level, possess more clinical experience, and are capable of taking the role of charge nurse in a nursing unit. Within the demographic data obtained, it was noted that $58 \%$ of the participants were PNIs and 24\% were PNIIs, suggesting that these nurses had more clinical experience and were able to function at a more advanced and independent level. These factors could have also influenced on their perception and coping with stress, and personality hardiness characteristics. 


\section{CONCLUSION}

In conclusion, this study provided greater insight into the study of critical care nurses' perception of stress, coping with stress, and personality hardiness characteristic. Results of this study also provided an avenue for investigation of other possible variables. Analysis of the results obtained demonstrated that critical care nurses do possess higher levels of personality hardiness characteristics. This study also revealed that critical care nurses are able to cope effectively regardless of their perception of stress.

\section{IMPLICATIONS}

Findings of this study imply that critical care nurses do possess the ability to cope with stress under stressful situations. Previous literature has supported the issue of critical care nurses being exposed to stress in the workplace (Erlen \& Sereika, 1997) and being susceptible to burnout if not able to cope with such stress appropriately (Boyle et al., 1991). This study also provided updated information as to the critical care nurses' perception of stress, particularly in this population. They had moderate perception of stress and were able to cope regardless of their perception of stress. With regards to hardiness, this population appeared to reach towards the higher end of the scale, meaning that they had hardy personality traits. As it has been noted in previous studies, hardiness has been associated with individuals' increased ability to cope with stressful conditions (Kobasa, 1979). The concept of hardiness is a construct with a widespread appeal for research and yet with a pressing need to be carefully analyzed (Mowinski and Staggers, 1994). 
This study poses future implication for investigation of critical care nurses' coping with stressors and their potential for burnout, as well as any possible correlations that may exist between the two variables. Other future issues to address may include the identification and/or development of valid tools that may assist the researcher in the identification of those particular stressors that critical care nurses may face daily in their work environment. This study further provides an opportunity to address other variables that may have an influence on nurses' hardiness personality and coping with stress, such as those noted in the demographics of this particular population (age, gender, years of nursing service, level of education). Other variables that may also be taken into consideration for future investigation include the relationship between ethnicity and coping; as well as the level of job satisfaction, and sense of belonging that may encourage some nurses to remain in a job setting for an extensive length of time. These factors may also play a role in the nurses' sense of challenge, control, and commitment that may contribute to their hardiness personality.

\section{LIMITATIONS}

This study posed some limitations, such as the modest response of 50 participants from a convenience sample of 100 registered nurses from a clinical facility. Possible reasons to explain the smaller response may have been related to the concern noted by some participants of the implications that an informed consent posed for them. The participants were reassured that their anonymity would be maintained, and that findings of the study would be released as group results. A copy of the signed informed consent was also provided to the participants. Another possible reason to sustain the 
modest response rate included the timing of this study, as participation included seasonal / per diem staff who worked in different units on an as needed basis. This study took place during a period of transitions in the workplace. These nurses were also working long hours under trying times of high patient/nurse ratio, which made their response rate significant in itself. To overcome the sample limitation, the incorporation of other facilities may have provided a more heterogeneous sample for study. This would have resulted in an increased validity for the correlation of all three scales.

Another limitation was that of those who responded, some questionnaires were partially filled out or not filled out at all. Those questionnaires were therefore discarded. Possible reasons to consider may have related to the presence of an informed consent to be signed prior to participation. Another reason could have been related to the length of the questionnaires, which may have represented another limitation for the population given their possible busier schedules and personal commitments. A smaller version of the instruments may have increased the sample's response to the study. And last, further studies involving the administration of the instruments applied in this study or the use of other alternative instruments may have been considered since there were no previous studies that applied all three instruments together as gathered from the literature review. Mowinski and Staggers (1994) cite the importance of careful selection of instruments for data collection in order to match the instrument to the population, given the availability of different instruments with which to measure hardiness. The theoretical sense of how hardiness functions is unclear in the nursing literature, as hardiness could have a direct (main), indirect (mediating), or interactive 
(moderating or buffering) effects in the stress - health relationship (Mowinski and Staggers, 1994).

\section{RECOMMENDATIONS}

1. Development of valid instruments capable of measuring specific stressors in the critical care setting in correlation with the critical care nurses' perception/ coping with stress.

2. Study of other variables such as culture and hours of work schedule (8-hour shifts versus 12 -hour shifts versus 16 -hour shifts), which may have an influence on the nurses' hardiness personality and coping with stress.

3. Further studies involving the use of shorter versions of the present instruments or the use of other instruments that may include measuring other variables such as ethnicity and religion.

4. Further research evaluating the difference in coping and hardiness from a healthy perspective versus an ill perspective, since there have been more studies of hardiness personality involving chronically ill populations.

5. More research focused on the identification of interventions geared towards the enhancement of hardiness personality characteristics, taking into consideration the dimensions of commitment, control, and challenge.

6. Study of the relationship between the sense of belonging and job satisfaction in the critical care population, which may also play a key role in the nurses' retention in a particular job setting. 
7. Research focused towards the relationship between maturity in terms of the years of nursing experience and the nurses' sense of belonging and satisfaction in their work setting.

Further exploration of these issues will enhance our understanding of stress, coping, and hardiness in Nursing. Further interventions may also be implemented to foster the nurses' hardiness personality characteristics and coping with stress, preventing "those who are brightly burning from becoming burned out" (Boyle et al., 1991, p. 857). 


\section{REFERENCES}

Bednash, G. (2000). The decreasing supply of registered nurses. Inevitable future or call to action? JAMA, 283 (22), 2985-2987.

Benoliel, J. Q. , Mc Corkle, R., Georgiadou, F., Denton, T., \& Spitzer, A. (1990). Measurements of stress in clinical nursing. Cancer Nursing, 13 (4), 221-228.

Boyle, A. , Grap, M. J., Younger, J. , \& Thornby, D. (1991). Personality hardiness, ways of coping, social support, and burnout in critical care nurses. Journal of Advanced Nursing, 16 (7): 850-857.

Carver, C. S., Scheier, M. F., \& Weintraub, J. K. (1989). Assessing coping strategies: A theoretically based approach. Journal of Personality and Social Psychology, 56 (2): 267-283.

Cohen, S. , Kamarck, T., \& Mermelstein, R. (1983). A global measure of perceived stress. Journal of Health and Social Behavior, 24 (December): 385-396.

Erlen, J. A. , \& Sereika, S. M. (1997). Critical care nurses, ethical decisionmaking and stress. Journal of Advanced Nursing, 26, 953-961.

Furukawa, M. M. (1996). Meeting the needs of the dying family. Critical Care Nurse, 10 (1): 51-56.

George, J. B. (1995). Nursing Theories. The base for professional nursing practice. Norwalk, Connecticut: Appleton \& Lange.

Holcombe, S. (1995). Creating an environment to support hardiness and quality patient care. Seminars for Nurse Managers, 3 (3): 115-118.

Houston, K. (1993). Do critical care nurses face burnout, PTSD, or is it something else? Getting help for the helpers. AACN Clinical issues in critical care nursing, 4 (3): 558-565.

Humphrey, J. H. (1988). Stress in the nursing profession. Springfield, Illinois: Charles C. Thomas Publisher.

Jacobson, S. F. , \& McGrath, H. M. (1983). Nurses under stress. New York: Wiley Medical Publishing.

Jackson, I. (1997). Coping with stress. Nursing Times, 93, (29): 81-82.

Kobasa, S. C. (1979). Stressful life events, personality, and health: an inquiry into hardiness. Journal of Personality and Social Psychology, 37 (1): 1-11. 
Kobasa, S. C. , Maddi, S. R. , \& Kahn, S. (1982). Hardiness and Health: A prospective study. Journal of Personality and Social Psychology, 42 (1): 168-177. McGraw-Hill.

Lazarus, R. (1966). Psychological Stress and the Coping Process. New York:

Lazarus, R. S. (1976). Patterns of Adjustment. Third edition. U.S.A.: McGrawHill Book Company.

Lazarus, R. S. , \& Lazarus, B. N. (1994). Passion and reason. Making sense of our emotions. New York: Oxford University Press, Inc.

Lobb, M. , \& Reid, M. (1987). Cost effectiveness at what price? An investigation of staff stress and burnout. Nursing Administration Quarterly, 12 (1): 5.

Monet, A. , \& Lazarus, R. S. (1991). Stress and coping: an anthology. $3^{\text {rd }}$. Ed. New York: Columbia University Press.

Moore Schaefer, K. , \& Peterson, K. (1992). Effectiveness of coping strategies among critical care nurses. Dimensions of Critical Care Nursing, 11 (1), 28-34.

Mowinski, B. , \& Staggers, N. (1994). A critical analysis of hardiness. Nursing Research, 43 (5), 274-281.

Pollock, S. E. (1984). Adaptation to stress. Texas Nursing, 58 (10), 12-13.

Pollock, S.E. (1984). The stress response. Critical Care Quarterly, 6 (4), 1-14.

Pollock, S. E. (1986). Human responses to chronic illness: Physiologic and psychosocial adaptation. Nursing Research, 35 (2): 90-95.

Pollock, S. E. (1989). The hardiness characteristic: a motivating factor in adaptation. Advanced Nursing Science, 11 (2), 53-62.

Pollock, S. E. , Christian, B. J. , \& Sands, D. (1990). Responses to chronic illness: analysis of psychological and physiological adaptation. Nursing Research, 39 (5): 300-304.

Pollock, S. E., \& Duffy, M. E. (1990). The Health-Related Hardiness Scale: Development and Psychometric Analysis. Nursing Research, 39 (4): 218 - 222.

Polit, D. F. , \& Hungler, B. P. (1999). Nursing Research. Principles and Methods. $6^{\text {th }}$ Edition. Philadelphia, PA: Lippincott. 
Roy, C. (1971). Introduction to Nursing: an adaptation model. New Jersey: Appleton-Century-Crofts.

Roy, C. , \& Andrews, H. A. (1991). The Roy adaptation model: The definitive statement. Norwalk: CT: Appleton \& Lange.

Sawatzky, J. V. (1996). Stress in critical care nurses: Actual and perceived. Heart \& Lung, 25 (5): 409-17.

Selye, Hans. (1956). The stress of Life. New York: New York: McGraw - Hill Book Company.

Selye, Hans. (1974). Stress without distress. New York: J. B. Lippincott Co.

Selye, Hans. (1979). The stress of my life. A scientist's memoirs. Second edition. New York: New York: Van Nostrand Reinhold Company.

Simoni, P. S. and Paterson, J. J. (1997). Hardiness, coping, and burnout in the nursing workplace. Journal of Professional Nursing, 13 (3), 178-185.

Winter-Collins, A. , \& McDaniel, A. M. (2000). Sense of belonging and new graduate job satisfaction. Journal for Nurses in Staff Development, 16 (3), 103-111.

Zeidner, M. , \& Endler, N. S. (1996). Handbook of coping. Theory, research, applications. New York: John Wiley \& Sons, Inc. 
APPENDIX A:

COVER LETTER 
Dear colleague:

My name is Catherina Chang and I am conducting a research study concerning the relationship between personality hardiness and critical care nurses' perception and coping with stress in the critical care environment. I am a Graduate Nursing student and I am conducting this research in partial fulfillment of the requirements for the Master of Science Degree in Nursing at Florida International University in Miami, Florida. This research problem was selected for its potential contribution in the expansion of the body knowledge of Nursing in the area of Critical Care Nursing as it will focus on the critical care nurses' coping with stress in their present work setting.

Your participation in this study is voluntary and you have the right to refuse to participate or withdraw from the study at any time without any negative consequences. There are four questionnaires enclosed, which you are kindly asked to fill out. One questionnaire will ask you about your age, gender, level of education, number of years in present job and nursing experience, work schedule and job classification. The second questionnaire will ask about your perception of stress in the last month. The third questionnaire will ask you to indicate the way you feel and act under stressful events. And the last questionnaire will ask you to indicate the level of agreement or disagreement that you may have towards certain health statements. There are no right or wrong answers. Completion of these questionnaires should take an approximate time of 20 of 30 minutes on a one-time basis.

Your responses will be kept strictly confidential, as results of this study will be revealed on a group basis. Your name will not be revealed in any report of this study, as all responses will be kept anonymous. There are no known risks or benefits involved in your participation in this study. You are also encouraged to keep this letter for future reference. If at any time, you have a question or desire to have further information regarding this study, you may contact Catherina Chang, ARNP student at (305)225-9620, or Dr. John Lowe at (305)919-5376.

Thank you for the courtesy of your time.

Sincerely,

Catherina Chang, R.N., B.S.N.

Florida International University

Graduate Nursing Student

Master in Science in Nursing

Adult Advanced Registered Nurse Program 


\title{
INFORMED CONSENT
}

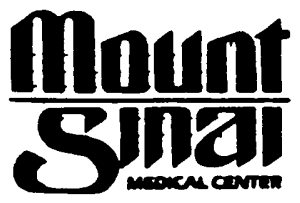

\author{
Relationship between Personality Hardiness and Critical Care Nurses' Perception and Coping \\ with Stress in the Critical Care Environment
}

YOU ARE ASKED TO READ THE FOLLOWING FORM TO MAKE SURE THAT YOU COMPLETELY UNDERSTAND WHAT WILL HAPPEN IF YOU AGREE TO TAKE PART IN THIS RESEARCH STUDY. SIGNING THIS FORM MEANS THAT THE STUDY HAS BEEN EXPLAINED TO YOU AND THAT YOU GIVE YOUR PERMISSION TO TAKE PART. THE FEDERAL GOVERNMENT REQUIRES YOUR APPROFAL IN WRITING BEFORE YOU TAKE PART IN ANY RESEARCH STUDY. IT IS IMPORTANT THAT YOU KNOW WHAT WILL TAKE PLACE AND WHAT RISKS ARE INVOLVED BEFORE YOU DECIDE WHETHER OR NOT TO TAKE PART IN THIS STUDY.

\section{RESEARCH PURPOSE AND DURATION}

You are being asked to take part in this research study. The purpose of this study is to investigate the relationship between personality hardiness and critical"care nurses' perception and coping with stress in the critical care environment. Your participation will last for approximately 20-30 minutes.

\section{PROCEDURES}

If you agree to take part in this study, the nurse investigator will ask you to complete four questionnaires. The first questionnaire asks questions regarding demographic data (age, gender, level of education, years working at present job, years of mursing experience, work schedule, and job classification). The second questionnaire asks that you indicate your perceptions of stress under certain circumstances within the last month. The third questionnaire asks that you rate the way you may act and feel under certain stressful events. The fourth questionnaire asks that you indicate the level of agreement or disagreement that you may have towards certain health statements. It should take you approximately $20-30$ minutes to complete these questionnaires.

\section{RISKS OR DISCOMFORTS}

Except for the inconvenience of time, there is little anticipated risk or discomfort associated with being in this study.

\section{BENEFITS TO YOU}

There are no direct benefits to you for being in the study. However, a possible benefit is that the findings may help nurses learn to cope with stress.

\section{ALTERNATIVE PROCEDURES OR FORMS OF THERAPY}

Your alternative is to choose not to participate in this study.

\section{COST TO YOU FOR TAKING PART IN THE RESEARCH STUDY}

There is no cost to you by taking part in the study.

Participant Initials

Date

04-21-00 
You will not be paid for taking part in the study.

\section{CONFIDENTLALITY}

All information which refers to, or can be identified with you, will remain confidential to the extent permitted by the law. No information will be revealed about you or your part in this study, without your permission, or the permission of your legally authorized representative, except that which may be necessary for the Research Committee, the Food and Drug Administration, and the sponsoring company to satisfy their legal requirements for review of the project.

\section{COMPENSATION FOR RESEARCH-RELATED INJURY}

Financial compensation for research-related injury or loss of wages is not available.

\section{WHOM TO CONTACT FOR ANSWERS}

If you have a problem related to taking part in this study which you do not understand, please contact the Principal Investigators in charge of the study at once.

Catherina Chang, RN, BSN

Nurse Educator

Nursing Education

Mount Sinai Medical Center

Work (305) 674-2573 home (305) 225-9620
Patricia R. Messmer, PhD, RN, C, FAAN

Director of Nursing Research

Mount Sinai Medical Center

Office (305) 674-2335 eve (954) 989-8286

Should you wish further information regarding research participants' rights, please contact the Mount Sinai Office of Research Administration at (305) 674-2790.

\section{PARTICIPATION IS VOLUNTARY}

Taking part of this study is voluntary. You may choose not to take part or may leave the study at any time. Leaving the study will not result in any penalty or loss of benefits to which you are entitled.

We will tell you about new information that may affect your health, welfare, or willingness to stay in this study.

\section{I HAVE READ, UNDERSTOOD, AND RECEIVED A COPY OF THIS INFORMED CONSENT FORM AND AGREE TO PARTICIPATE.}

Printed Name, Address \& Telephone \# of Participant

Printed Name of Witness Date

$\overline{\text { Signature of Principal Investigator Date }}$

Revised 04-21-00
Signature of Participant Date

Signature of Witness $\quad$ Date 
APPENDIX B:

DEMOGRAPHIC DATA SURVEY 
Please mark with an " $\mathrm{X}$ " the correct information:
Age: 20-25
26-30
$31-35$
$36-40$
41-45
46-50
$51-55$
$56-60$
61 or older

Gender: Male

Female

Highest level of education completed:

Diploma

A.D.N.

B.S.N.

B.S. in another field

M.S.N.

M.S. in another field

Ph. D.

Number of years in present job:

$1-5$

6-10

$11-15$

$16-20$

$21-25$

26-30

31 and above

Number of years of nursing experience:

$1-5$

6-10

11-15

$16-20$

$21-25$

26-30

31 and above

Work schedule: Day shift

Evening shift

Night shift

Job classification: PNI

PNII

PNIII

Per Diem 
APPENDIX C:

PERCEIVED STRESS SCALE 


\section{Perceived Stress Scale}

Items and instructions for Perceived Stress Scale:

The questions in this scale ask you about your feelings and thoughts during the last month. In each case, you will be asked to indicate how often you felt or thought a certain way. Although some of the questions are similar, there are differences between them and you should treat each one of them as a separate question. The best approach is to answer each question fairly quickly. That is, don't try to count up the number of times you felt a particular way, but rather indicate the alternative that seems like a reasonable estimate.

For each question choose from the following alternatives:

0. never

1. almost never

2. sometimes

3. fairly often

4. very often

1. In the last month, how often have you been upset because of something that happened unexpectedly?

2. In the last month, how often have you felt that you were unable to control the important things in your life?

3. In the last month, how often have you felt nervous and "stressed"? $\quad \begin{array}{lllll}0 & 1 & 2 & 3 & 4\end{array}$

4. In the last month, how often have you dealt successfully with irritating life hassles? 
5. In the last month, how often have you felt that you were effectively coping with important changes that were occurring in your life?

$\begin{array}{lllll}0 & 1 & 2 & 3 & 4\end{array}$

6. In the last month, how often have you felt confident about your ability to handle your personal problems?

$\begin{array}{lllll}0 & 1 & 2 & 3 & 4\end{array}$

7. In the last month, how often have you felt that things were going your way?

$$
\begin{array}{lllll}
0 & 1 & 2 & 3 & 4
\end{array}
$$

8. In the last month, how often have you found that you could not cope with all the things that you had to do?

$\begin{array}{lllll}0 & 1 & 2 & 3 & 4\end{array}$

9. In the last month, how often have you been able to control irritations in your life?

$$
\begin{array}{lllll}
0 & 1 & 2 & 3 & 4
\end{array}
$$

10. In the last month, how often have you felt that you were on top of things?

$$
\begin{array}{lllll}
0 & 1 & 2 & 3 & 4
\end{array}
$$

11. In the last month, how often have you been angered because of things that happened that were outside of your control?

$\begin{array}{lllll}0 & 1 & 2 & 3 & 4\end{array}$

12. In the last month, how often have you found yourself thinking about things that you have to accomplish?

$\begin{array}{lllll}0 & 1 & 2 & 3 & 4\end{array}$

13. In the last month, how often have you been able to control the way you spend your time?

$\begin{array}{lllll}0 & 1 & 2 & 3 & 4\end{array}$

14. In the last month, how often have you felt difficulties were piling up so high that you could not overcome them? 
APPENDIX D:

COPE QUESTIONNAIRE 


\section{COPE Questionnaire}

We are interested in how people respond when they confront difficult or stressful events in their lives. There are lots of ways to try to deal with stress. This questionnaire asks you to indicate what you generally do and feel, when you experience stressful events. Obviously, different events bring out somewhat different responses, but think about what you usually do when you are under a lot of stress.

Then respond to each of the following items by writing the number of your answer from the choices listed below in front of each statement. Please try to respond to each item separately in your mind from each other item. Choose your answers thoughtfully, and make your answers as true for you as you can. Please answer every item.

There are no "right" or "wrong" answers, so choose the most accurate answer for you - not what you think "most people" would say or do. Indicate what you usually do when you experience a stressful event.

$1=$ I usually don't do this at all.

$2=$ I usually do this a little bit.

$3=$ I usually do this a medium amount.

$4=$ I usually do this a lot.

1. I try to grow as a person as a result of the experience.

2. I turn to work or other substitute activities to take my mind off things.

3. I get upset and let my emotions out.

4. I try to get advice from someone about what to do.

5. I concentrate my efforts on doing something about it. 
6. I say to myself "this isn't real".

7. I put my trust in God.

8. I laugh about the situation.

9. I admit to myself that I can't deal with it, and quit trying.

10. I restrain myself from doing anything too quickly.

11. I discuss my feelings with someone.

12. I use alcohol or drugs to make myself feel better.

13. I get used to the idea that it happened.

14. I talked to someone to find out more about the situation.

15. I keep myself from getting distracted by other thoughts or activities.

16. I daydream about things other than this.

17. I get upset, and am really aware of it.

18. I seek God's help.

19. I make a plan of action.

20. I make jokes about it.

21. I accept that this has happened and that it can't be changed.

22. I hold off doing anything about it until the situation permits.

23. I try to get emotional support from friends or relatives.

24. I just give up trying to reach my goal.

25. I take additional action to try to get rid of the problem.

26. I try to lose myself for a while by drinking alcohol or taking drugs.

27. I refuse to believe that it has happened.

28. I let my feelings out. 
29. I try to see it in a different light, to make it seem more positive.

30. I talk to someone who would do something concrete about the problem.

31. I sleep more than usual.

32. I try to come up with a strategy about what to do.

33. I focus on dealing with this problem, and if necessary let other things slide a little.

34. I get sympathy and understanding from someone.

35. I drink alcohol or take drugs, in order to think about it less.

36. I kid around about it.

37. I give up the attempt to get what I want.

38. I look for something good in what is happening.

39. I think about the best way to handle the problem.

40. I pretend that it hasn't really happened.

41. I make sure not to make matters worse by acting too soon.

42. I try hard to prevent other things from interfering with my efforts at dealing with this.

43. I go to movies or watch TV, to think about it less.

44. I accept the reality of the fact that it happened.

45. I ask people who have had similar experiences what they did.

46. I feel a lot of emotional distress and I find myself expressing those feelings a lot.

47. I take direct action to get around the problem.

48. I try to find comfort in my religion. 
49. I force myself to wait for the right time to do something.

50. I make fun of the situation.

51. I reduce the amount of effort I'm putting into solving the problem.

52. I talked to someone about how I feel.

53. I use alcohol or drugs to help me get through it.

54. I learn to live with it.

55. I put aside other activities in order to concentrate on this.

56. I think hard about what steps to take.

57. I act as though it hasn't even happened.

58. I do what has to be done, one step at a time.

59. I learn something from the experience.

60. I pray more than usual.

61. When you are under stress, do you usually feel

(1) that you definitely can do something about the situation

(2) that you probably can do something about the situation

(3) that you probably can do nothing about the situation, or

(4) that you definitely can do nothing about the situation. 


\section{APPENDIX E:}

HEALTH- RELATED HARDINESS SCALE 


\section{Health - Related Hardiness Scale}

This is a questionnaire designed to determine the way in which different people view certain important issues related to their health. Each item is a belief statement, which you may agree or disagree. Beside each statement is a scale which ranges from strongly disagree (1) to strongly agree (6). For each item, we would like you to circle the number that represents the extent to which you disagree or agree with the statement. Please make sure that you answer every item and that you circle only one number per item. Thank you for taking the time to complete this questionnaire.

\begin{tabular}{cc} 
DISAGREE & AGREE \\
\cline { 2 - 3 } S M S & S M S \\
T O L & L O T \\
R D I & I D R \\
O E G & G E O \\
N R H & H R N \\
G A T & T A G \\
L T L & L T L \\
Y E Y & Y E Y \\
L & L \\
Y & Y
\end{tabular}

1. Involvement in health

$\begin{array}{lll}1 & 2 & 3\end{array}$

456 promotion activities is stimulating.

2. I can avoid illness if I

123

456 take care of myself.

3. I find it difficult 123

456 to be enthusiastic about good health.

4. Luck plays a big part 123 456 in determining how soon I will recover from an illness. 
5. No matter how hard I

123

456 try to maintain my

health, my efforts

will accomplish

very little.

6. I am in control of my health.

7. I admire people who

123

456 work hard to improve their health.

8. Good health is more

123

$\begin{array}{lll}4 & 5 & 6\end{array}$ important to me than financial security.

9. My good health is largely a matter of good fortune.

10. No matter what I do,

123

456

I'm likely to get sick.

11. I find it boring to

123

456 eat and exercise properly to maintain my health.

12. The main thing which

123

456 affects my health is what I myself do.

13. Changes taking place

123

456 in health care are not exciting to me.

14. I find people who are involved in health promotion interesting.

15. Setting goals for health is unrealistic. 
16. Most things that

123

456 affect my health happen to me by accident.

17. Changes taking place

$\begin{array}{lll}1 & 2 & 3\end{array}$

456 in health care will have no effect on me.

18. If I get sick, it is my 123

456 own behavior that determines how soon I get well.

19. I do not find it 123 456 interesting to learn about health.

20. I will stay healthy if it's meant to be.

21. I am not interested in exploring new ways to improve my health.

22. No matter what I do, 123

456 if I am going to get sick, I will get sick.

23. I feel no need to try

123

456

123

456 to maintain my health because it makes no difference anyway.

24. The current focus on 123 456 health promotion is a fad that will probably disappear.

25. No matter how hard I work to promote health for society, it never seems to improve. 
26. Our society holds no

123

$\begin{array}{lll}4 & 5 & 6\end{array}$ worthwhile goals or values about health.

27. If I take the right actions, I can stay healthy.

28. I get excited about the possibility of improving my health.

29. I am determined to be

123

456 as healthy as I can be.

30. When my health is

123

456 threatened, I view it as a challenge that must be overcome.

31. I read everything I

123

456 can about health.

32. I can be as healthy $\begin{array}{lll}1 & 2 & 3\end{array}$

$\begin{array}{lll}4 & 5 & 6\end{array}$ as I want to be.

33. When something goes

123

$\begin{array}{lll}4 & 5 & 6\end{array}$ wrong with my health, I do everything I can to get at the root of the problem.

34. I have little influence 123

456 over my health.

Copyright, 1990, Susan E. Pollock, Ph. D. 


\section{APPENDIX F}

\section{PERMISSION TO USE INSTRUMENTS}


Carnegie Mellon University

Department of Psychology Pittsburgh, PA 15213

Telephone: (412) 268-2336

Fax: (412) 268-3294

February 14,2000

Catherina Chang

917 Northwest $135^{\text {th }}$ Court

Miami, FL 33182

RE; PSS Permission

Dear Ms.Chang:

You may use the PSS in your research. In the future, please reference our web site, as there is a lot of information available. It can be located from the Carnegie Mellon Psychology web site, (www.psy.cmu.edu), or via the direct address:

http://kungfu.psy.cmu.edu/ scohen/.

Please let me know how the work turns out. Good luck.

Sincerely,

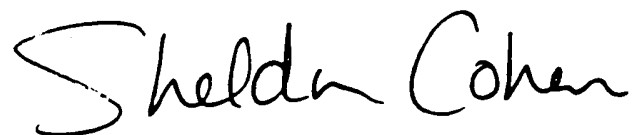

Sheldon Cohen

Professor 


\section{TEXAS TECH UNIVERSITY HEALTH SCIENCES CENTER}

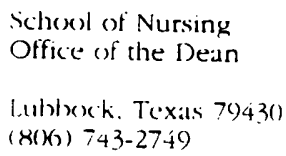

\section{Dear Colleague:}

Thank you for your interest in the Health Related Hardiness Scale (HRHS). I am happy to make this instrument available to you for research as a way of collecting data from various populations. The requirements for using this instrument are listed below. After I receive this form and a copy of your abstract, I will mail you a copy of the instrument.

My policy is to grant permission to use the HRHS for research purposes if I:

1. receive an abstract of the proposed research;

2. am assured of receiving the results of the study;

3. receive a copy of the reliability and validity estimates obtained;

4. am assured that no further psychometric analyses will be done; and

5. am credited with authorship in any use, associated report, or publication involving the instrument.

I agree to the above requirements and have enclosed an abstract of my proposed research.

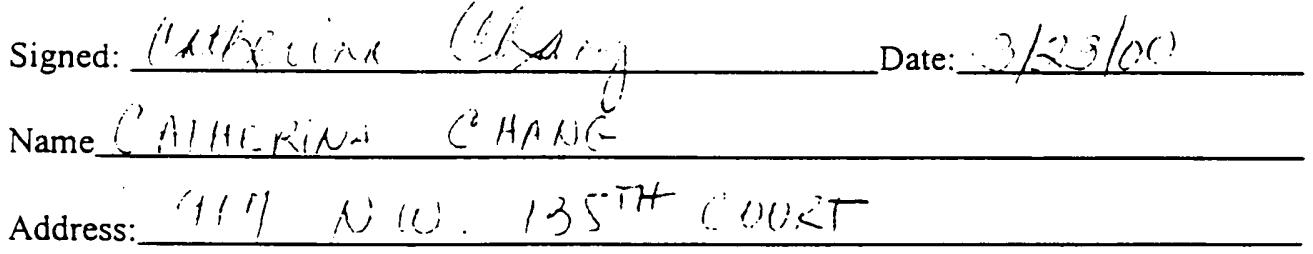

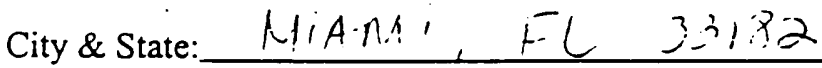

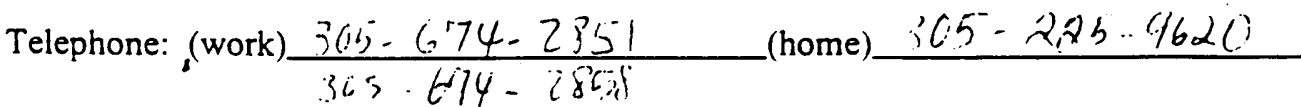
Sincerely

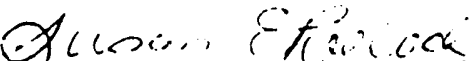
Susan E. Pollock, PhD, RN, FAAN

Professor and Associate Dean for Research School of Nursing

Texas Tech Health Sciences Center 3601 4th Street

m: Iwinword vesearch hrhslcontract.496 Lubbock, Texas 79430 


\section{APPENDIX G}

\section{INSTITUTIONAL REVIEW BOARD}

APPROVAL OF RESEARCH 


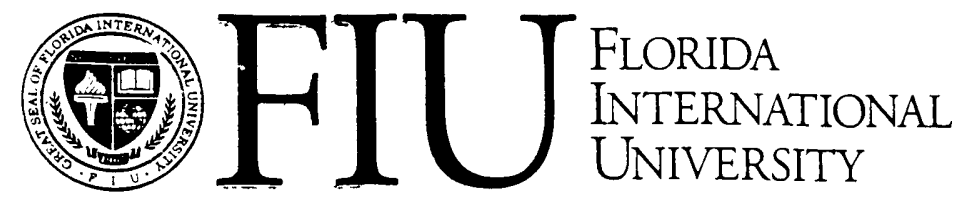

Hope, Knowledge, and Opportunity

\section{INSTITUTIONAL REVIEW BOARD APPROVAL FORM}

This is to certify that the program of research listed below has been reviewed by the Instutional Review Board (IRB) representative for the School of Nursing in accordance with the requirements of 45 CFR 46 , including its relevant status.

\section{Principal Investigator / Project Director: Catherina I. Chang}

Faculty Supervisor (if PI is a student): $\quad$ Dr. John Lowe, RN, PhD

Project Title: Relationship Between Personality Hardiness and Critical Care Nurses' Perception And Coping with Stress in the Critical Care Environment

* Date of IRB Review \& Approval: 11 April, 2000

Full Board Review

Expedited Review

_ _ Exempt Research

" The approval of this project is valid for one year starting from the date above. A status report of the project must be on going past one year, and upon completion, a summary of the research project must be submitted to the Chair of the University Research Council (URC).

\section{Comments:}

\section{Full Approval}

The official signing below certifies that the information provided on this form is correct and the institution assumes responsibility for conducting further reviews, approvals, and submission of certification.

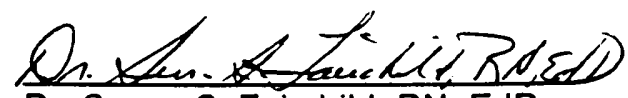

Dr. Susan S. Fairchild, RN, EdD

Date: 11 April, 2000

IRB/URC Representative - School of Nursing

cC: IRB File-SON; URC

\footnotetext{
COLLEGE OF HEALTH SCIENCES

School of Nursing

3000 N.E. 151 Street, AC II-230 • North Miami, Florida 33181-3000

relephone (305) 919-5915 • fax (305) 919-5395

www.funedu

Equal Opportunivy/Equal Acoes Employer and Insciturion • TDD via FRS 800 955-8771
} 


\section{AFFIRMATION OF COMPLIANCE AND ACCEPTANCE OF RESPONSIBILTTY}

I agree to follow the procedures outlined in this summary description and any atwachments. I undersiand that no contaci may be initialed with subjects unill I lave received approval of these procedures from the URC and have complied with any modifications required in Lonnection with that approval. I undersiand that additions 10 or changes in the procedures involving human subjects can only be made afler approval of the URC. I undcrsiand that I must prompily repon to the LRC any froblems with the nights or welfare of the human sunjects. I understand and will follow Flonda Internatioi bl Universily's policies concerning researeh with human subjects. I will do everything in my power to prolect the'righis and welfase of human subjects in my research project. (pelationship between Dersonality Hardinoss and critical care Nurses'

Perception and Coping with stress in the Critical Care Environment.

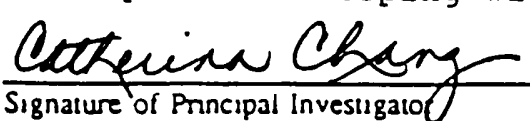

$\frac{02 / 14 / 00}{\text { Dale }}$

Catherina Ivetto Chang, R, N/, B,S.N.

Prinied name of Principal Invesizator

If the PI is a student. the faculty supervisor must sign below

I have read this application and assume responsibility for its accuracy and for superision of the proposed researsh project.
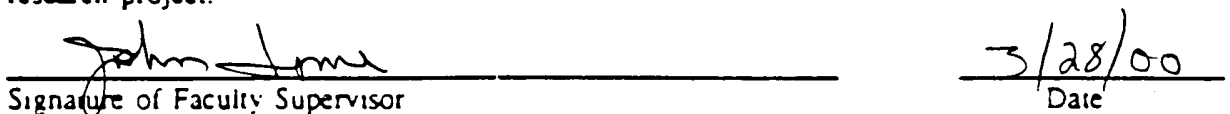

Signalure of Faculty Supervisor

,

John Lowe $\mathrm{PA} \mathrm{PhD}$

Frniced name of Faculiy Supen:sur

ACTION RECONERE. DED BY LRC “For URC use oniy."

Date: $4 / 1 /$ ard I Approved I I Changesiciarifications Requesied I I Require Full Board Revieu

Prinled name of LRC Charperson

Date:

( I Approved I /Changes/Clarifications Requested

( ) Require Full Board Reviex

Signature of URC Chairperson

Dare:

Signalure of URC Charperson 
FLORIDA INTERNATIONAL UNIVERSITY

UNIVERSITY RESEARCH COUNCIL (URC)

APPLICATION FOR APPROVAL OF RESEARCH INVOLVING HUMAN SUBJECTS

1. PROJECT TITLE: RELATIONSHIP BETWEEN PERSONALITY HARDINESS

AND CRITICAL CARE NURSES' PERCEPTION OF STRESS AND COPING

IN THE CRITICAL CARE ENVIRONMENT.

2. PRINCIPAL INVESTIGATOR: Catherina Ivette Chang

SS\#: $\underline{593-78-8132}$

Address: 917 N.W. $135^{\text {th }}$. Court. Miami, Fl $33182 \quad$ Phone \#: $\underline{\text { 305-225-9620 }}$

Position: ( ) Faculty (X) Graduate Student ( ) Undergraduate Student ( ) Other

1. FACULTY SUPERVISOR (if PI is a student): Dr. John Lowe. R.N., PhD.

2. STATUS OF PROJECT REVIEW:

(X) New project ( ) Revision of previously approved project ( ) Continuation of approved project.

5. BRIEF DESCRIPTION OF SUBJECTS

Number of subjects: minimum of 100.

Check all of the following categories that describe your research subjects:

(X) Males

(X) Females

( ) Minors (under 18 years old)

( ) Students (Please specify):

( ) Persons with Physical Disabilities (Please Specify):

( ) Persons with Mental/Psychological Disabilities (Please Specify):

( ) Persons with Physical or Mental Health Problems (Please Specify):

( ) Persons with No Known Disabilities and No Known Health Problems 
( ) Prisoners

( ) Pregnant women, fetuses, fetal material or placenta (Please Specify):

( ) Persons in Some Type of Program (Please Specify):

(X) Other Pertinent Information (Please Specify): Staff nurses in adult critical care units in a South Florida teaching hospital.

6. TYPE OF REVIEW REQUESTED:

( ) Exempt: Category \# (s):

(X) Expedited Review; Category \#(s): $\underline{9}$

( ) Full URC Review (Can be neither Exempted nor Expedited)

\section{RESEARCH OBJECTIVES}

The purpose of this study is to investigate the relationships between critical care nurses' perception of stress, their ability to cope with stress, and the level of hardiness personality they possess while working in the critical care environment. The following research questions will be addressed in this study:

What are the relationships between the hardy personality disposition in the critical care nurses and their perception of stress?

What is the relationship between the critical care nurses' perception of stress and their actual coping with stress?

To what extent is the level of hardiness influenced by demographic factors, such as (a) age, (b) gender, (c) level of education, (d) number of years in present job, (e) number of years of nursing experience, $(f)$ work schedule, and $(g)$ job classification?

\section{SUBJECT RECRUITMENT}

The sampling approach will be a convenience sample of registered nurses employed 
in the intensive care units of a South Florida teaching hospital. The target sample will include a minimum of 100 participants. Each prospective participant will be approached and provided with an introductory letter that explains the purpose of the study, potential risks and benefits, confidentiality, anonymity of the participant, and duration of the study. The researcher's name and telephone number will be included in the cover letter. There will be four questionnaires attached to the cover letter of the study. These questionnaires will be filled out by each participant and returned to the principal investigator within a period of two weeks.

\section{BENEFITS}

The participants will be informed in the cover letter that they will not receive any direct benefit from their participation in the study. Potential benefits of the study will include a better understanding of the role of hardiness in the nurses' perception and coping with stress in their work setting. The results of the study will contribute to the expansion of the body knowledge of Nursing as a better understanding of the effects of stress in the mental and physical well-being of nurses, which may have an impact on the delivery of patient care. Moreover, the results of the study will provide nursing leaders with an updated information on the subject of stress and hardiness. The development of programs and interventions that foster the personality disposition of hardiness could be implemented, not only for critical care nurses, but also for other staff nurses, and patients; leading to the development of an environment conducive to more effective health care.

\section{INFORMED CONSENT}

An informed consent form explaining: (a) the nature of the study, (b) voluntary 
participation of the critical care nurses, (c) the confidentiality of the participants' responses, (d) anonymity of the participants, (e) potential risks and benefits, and (f) liberty to ask questions, will be attached to the cover letter. The telephone numbers and names of the principal investigator and major professor will be provided in the consent form for the participants in case of any questions or concerns.

\section{CONFIDENTIALITY OF DATA}

The participants will be assured that the data gathered will be kept strictly confidential and anonymous as questionnaires will be given a code number. The code numbers assigned to each completed questionnaire, and the names of the individuals involved in the study will be kept in a locked file by the principal investigator for a period of three years. After such period, data will be appropriately discarded. The raw data will be handled strictly by the principal investigator, major professor, and statistician. Results of the study will be released in terms of group data.

\section{METHOD AND PROCEDURES}

Approval of the research proposal and permission to conduct the study will be obtained from the University Research Council and the South Florida teaching hospital's Institutional Review Board Committee where the study will take place. After such approval is obtained, the nurse managers of each critical care unit will be contacted and given information about the study one week prior to the delivery of questionnaires to the participants. The participants will be provided with an envelope containing the cover letter, informed consent form, and four questionnaires of the study. The participants will be informed about the study and its purpose. Those participants that do decide to participate in the study will be asked to drop their completed 
questionnaires into a marked box placed in the nurses' lounge. The principal investigator will empty the marked box on a weekly basis for a period of two weeks.

\section{STIMULUS MATERIALS}

The stimulus materials consist of:

(a) A Demographic survey that collects data on the variables of age, gender, level of education, number of years of nursing experience, number of years at present job, work schedule, and job classification.

(b) The Perceived Stress Scale developed by Cohen, Kamarck, and Mermelstein (1983).

(c) The Cope inventory developed by Carver, Scheier, and Weintraub (1989).

(d) The modified Health-Related Hardiness Scale developed By Pollock (1990).

\section{RISKS TO SUBJECTS}

There will be no social repercussions, economic demands, or legal risks incurred by the participants. Psychological risks are not greater than those faced in normal life. The cover letter and informed consent will inform the participants that their participation will be voluntary, and their answers to the questionnaires kept confidential and anonymous. 
March 30, 2000

Catherina Ivette Chang

Nursing

Mount Sinai Medical Center

RE: Review of Protocol No. 00-24-H-03 "Relationship Between Personality Hardiness and Critical Care Nurses' Perception and Coping With Stress in the Critical Care Environment"

Dear Ms. Chang:

The above referenced protocol has been given an expedited review and approval by Jose A. Adams, M.D., Chairman, Institutional Review Board of this Institution on March 30, 2000. You are now authorized to proceed with your research study. Please indicate the date of IRB approval on every copy of the informed consent form prior to obtaining the subject's consent.

Should any changes be made in your procedures, please notify the Committee immediately.

Your study will be subject to re-review by the Committee during regular intervals. You will be required to provide an update at that time. Appropriate forms will be sent to you in advance.

Thank you for your cooperation.

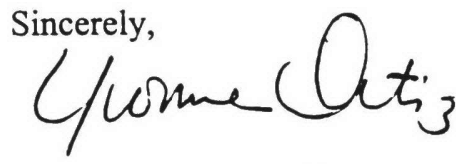

Yvonne Ortiz, Coordinator

Institutional Review Board 